
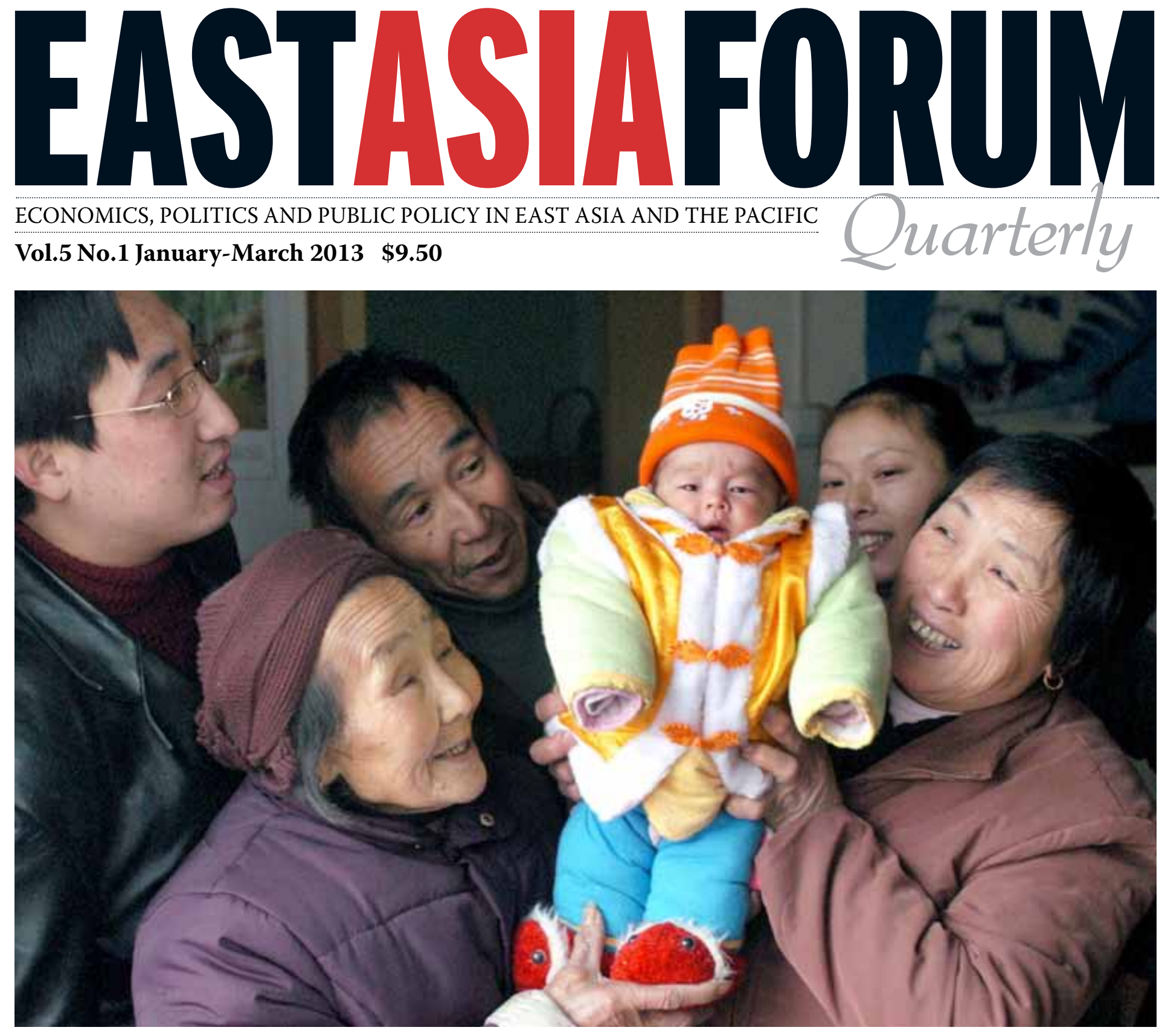

\title{
Demographic transition
}

Peter McDonald Low fertility: an East Asian dilemma

Wolfgang Lutz and Samir KC Human capital and the Asian Century

Amy Tsui Half a century of family planning

Gavin W. Jones Diversity in marriage patterns

Rafal Chomik and John Piggott Ageing societies, a race against time and more... 


\section{EASTASIAFORUM \\ Quarterly \\ ISSN 1837-5081 (print) \\ ISSN 1837-509X (online)}

\section{From the Editor's desk}

By 2050 Asia will add another billion to its already huge population of 4.3 billion. Somewhat perversely, demographers see this as a good result, not because the population will grow but because the outcome for 2050 is several billion lower than it would have been without the spread of control over human fertility that has occurred over the past four decades. Future population growth is confined almost entirely to South Asia and will be the result not of high birth rates but of large numbers of people in the childbearing ages, the product of past higher fertility.

The falls in birth rates across Asia mean that today there is a concentration of population in most Asian countries in the working ages. This highly desirable characteristic is known as the demographic dividend because it provides the opportunity for more productive investment of capital and for a stronger focus on developing the human capital of the next generation of workers, both essential features of economic development. This dividend has already proven to be effective in Japan and the Asian tiger economies, and is now evident in the development progress of countries such as Malaysia, Thailand, Indonesia and China. Other countries need to ensure that they capitalise on this potential.

Demography never stands still and those countries that were at the head of demographic change in the second half of the 20th century now find themselves facing the new challenges of very low fertility and very rapid ageing of their populations. Rapid falls in mortality rates have also contributed to ageing and to a shift in the burden of disease to older-age chronic illnesses. The articles in this issue address the past, the present and the future of demography in Asian countries and assess the causes and consequences of this spectacular transition.

\section{Peter McDonald}

\section{eastasiaforum.org}

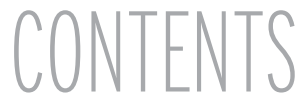

3 ZHONGWEI ZHAO

Population change shaping Asia's future

\section{TOMOKO KINUGASA}

Second dividend holds promise of sustained rewards

7 WOLFGANG LUTZ AND SAMIR KC

The Asian century will be built on human capital

9 BHAKTA B. GUBHAJU

Demographic dividends: a window of opportunity

11 RAFAL CHOMIK AND JOHN PIGGOTT

Ageing societies involved in a race against time

\section{HEATHER BOOTH}

Asia's silver revolution

16 DIALOGUE: YI ZENG, JOHN KNIGHT

AND ZAI LIANG

China facing a declining working-age population

19 ADRIAN C. HAYES

Asia's consuming classes and the environment

21 HELEN JAMES

New families arise from nature's disasters

23 PETER MCDONALD

Low fertility: an East Asian dilemma

24 GAVIN W. JONES

Diversity in marriage patterns across the region

\section{AMY TSUI}

What half a century of family planning can contribute

28 BAOCHANG GU AND YAN CHE

Contraception, a family planning imperative

30 VINH DUC NGUYEN

Child mortality declines-just not quickly enough

32 BINOD NEPAL

AIDS: hopes and challenges

\section{GRAEME HUGO}

International migration in Asia's demographic transition
COVER PHOTO: Great-grandmother, grandparents and parents in Yichang city with a new baby. China's one-child policy is increasingly being seen as an impediment to growth. Some projections have the labour force declining by around 10 million people a year from 2025. Picture: AAP. 


\section{EVOLVING CERTAINTIES}

\section{Population change shaping Asia's future}

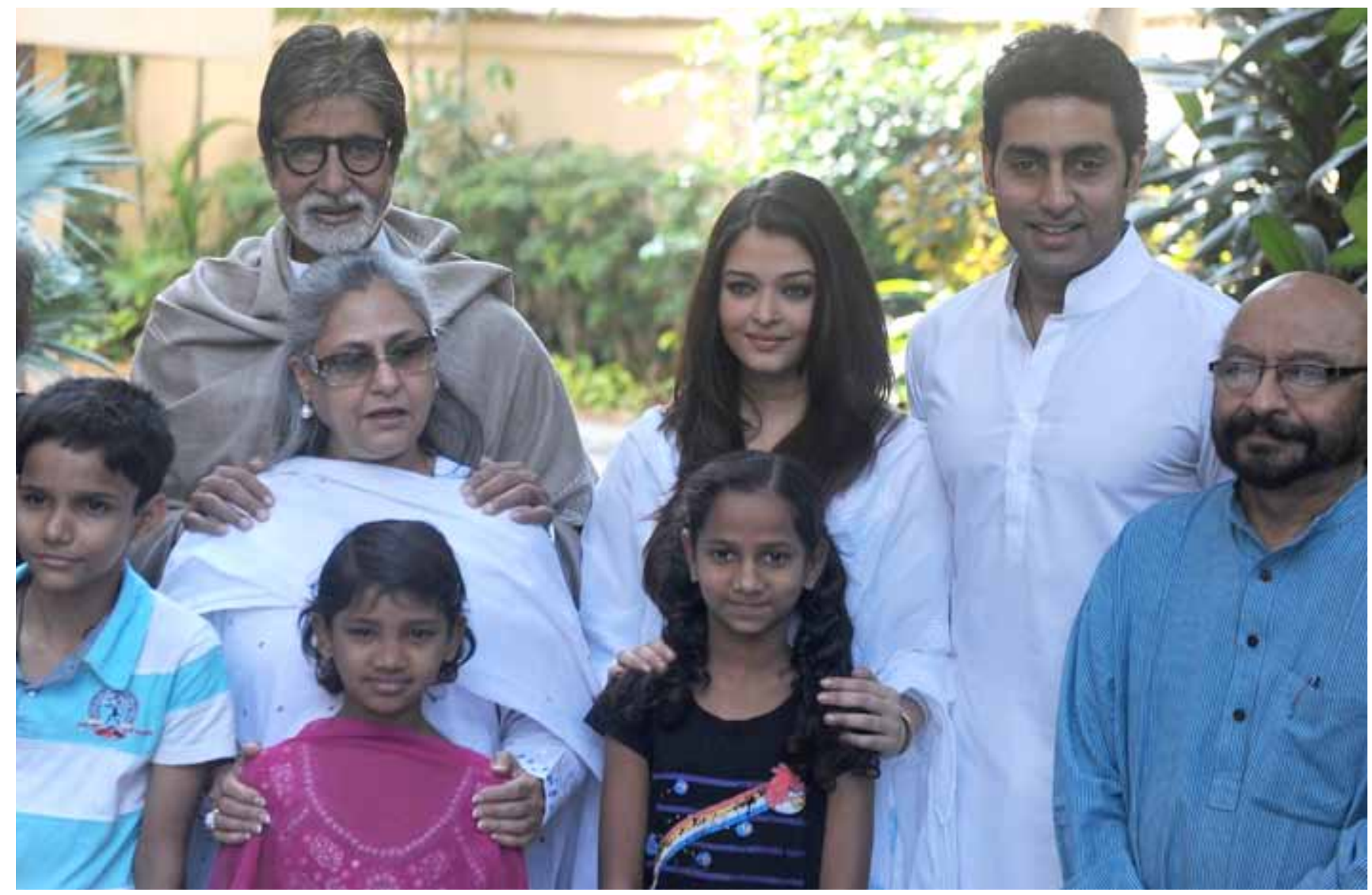

\section{ZHONGWEI ZHAO}

\section{A}

\section{SIA comprises around 50}

countries and territories, and its population of around 4.3 billion accounts for 60 per cent of the world total. In the 1950s, the Asian population as a whole was still in the early stages of demographic transition: fertility and mortality were both higher than the world average, with a total fertility rate (TFR) of 5.8 children per woman and a life expectancy of 43 years. Since then Asia has witnessed the most rapid demographic change in the world. The TFR has fallen to 2.2 children per woman and life expectancy has reached 70 years.

Yet great demographic diversity still exists. Asian populations have experienced remarkable demographic changes, but the process, magnitude and consequence of these changes have varied significantly. When examined by region, East Asia has led the change over the past six decadesthe lowest fertility and mortality rates in the world have been recorded in some East Asian populations in recent years. Southeast Asia is now slightly behind East Asia; the region's TFR has fallen from 6.1 to 2.1 children per
Bollywood actor Amitabh Bachahan, top left, with family and colleagues after announcing their support for Plan India, a charity dedicated to the protection and rights of newborn girls. Rapid population growth will continue to challenge countries in South Asia.

woman and life expectancy has risen from 42 to 71 years.

In contrast, fertility and mortality changes have been much smaller in the five Central Asian countries. Their TFR has declined from 4.6 to 2.5 children per woman and life expectancy has increased by only 13 years (from 55 to 68 years). 
EASTASIAFORUM

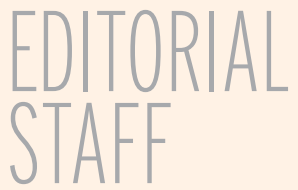

Issue Editors

Peter McDonald is Professor of

Demography and Director of

the Australian Demographic and Social

Research Institute at the Australian

National University.

Zhongwei Zhao is Professor at the Australian Demographic and Social Research Institute, College of Arts and Sciences, the Australian National University.

\section{Editors}

Peter Drysdale, Head, East Asia Forum and East Asian Bureau of Economic Research, Crawford School, ANU.

Shiro Armstrong, Executive Director, East Asia Forum and East Asian Bureau of Economic Research, Crawford School, ANU.

Editorial Staff

Mark Fabian, ANU.

Advertising

Sally Davis, eastasiaforum@next.com.au

\section{Editorial Advisers}

Peter Fuller, Max Suich.

\section{Production}

Peter Fuller, Words \& Pics.

\section{Original design}

Peter Schofield.

Email

Peter.Drysdale@anu.edu.au,

Shiro.Armstrong@anu.edu.au

\section{ANU E PRESS}

Published by ANU E Press The Australian National University Canberra ACT 0200, Australia Email: anuepress@anu.edu.au Web: http://epress.anu.edu.au
Demographic changes in West and South Asia have been far more notable than those in Central Asia but have been less dramatic in comparison with East and Southeast Asia.

Marked variations in fertility and mortality have helped to form different age structures and other demographic characteristics in these populations, which have had very different impacts on Asia's recent socioeconomic development. For the same reason, these countries and areas will also face very different demographic challenges in the near future. On the basis of these considerations and their current fertility and mortality levels, Asian populations can be divided broadly into three major groups, although there are some exceptions.

The first group consists of most East Asian populations and several countries in other parts of Asia. These populations completed their demographic transition some time ago. Their recent and current fertility levels are lower or much lower than 1.8 children per woman, and life expectancy tends to be higher than 74 years. Their recent population changes have opened the 'demographic window' to economic development, and most of these countries have experienced rapid economic growth in recent decades. Because of their very low fertility rates and remarkable reductions in mortality, these countries have witnessed and will continue to witness rapid ageing. Many of them have experienced or will soon experience a notable decline in the working-age population, or even a decline in the national population. The conventionally defined old-age dependency ratio will further increase in most of these countries. If their farbelow-replacement fertility levels are not reversed soon, the age structure of these populations will become even more top-heavy or biased towards old people.

The second group of countries, which is spread right across Asia and includes countries such as Turkey, Indonesia and Oman, has largely completed its demographic transition, but fertility levels are either slightly higher than replacement or have only reached this level recently. Their life expectancy is generally within the range of 70 to 75 years. Largely for this reason, the proportion of old people is still growing relatively slowly in these countries. Most of these populations will have low or declining dependency ratios over the next few decades, which, together with favourable development policies and adequate investment, could bring about the kind of rapid economic growth that we have seen in many group-one countries. Creating enough jobs will be a major challenge over the next $20-30$ years.

\section{$\mathbf{T}$} HE third group of countries is largely from South, Southeast and West Asia. Most of these countries are still in the late stages of demographic transition. Their fertility rates are still notably higher than replacement level and life expectancy is generally lower-in some cases much lowerthan 70 years. Rapid population growth will continue to be a major challenge for them, and some will see their current population more than double by the middle of the century.

The views expressed in East Asia Forum Quarterly are those of the individual authors and do not represent the views of the Crawford School, the Australian National University, EABER, EAF, or the institutions to which the authors are attached. 
This will lead to increased population density, a high dependency ratio and strong demand for employment-and these factors will put great pressure on socioeconomic development. In some of the group-two and group-three countries, the high population density, increasing demand for jobs and low standards of living will also produce a strong 'push' which could lead to increased international migration.

In the next $20-30$ years, fertility and mortality changes are likely to be relatively slow and steady in most Asian populations, although they may decline rapidly in some group-three countries. This is because after falling to a low level, mortality rates are very unlikely to bounce back dramatically unless the country is struck by catastrophic infectious disease, natural disaster or war. Similarly, in lowfertility populations, small fluctuations or a moderate increase in fertility may take place, but a drastic surge or reduction in fertility seems unlikely in the near future.

The considerable certainty about Asia's future demographic changes also stems from the impact of population momentum. Because of this, a number of major demographic trends in Asia have already been determined by the size and structure of the current population. While unexpected events or radical interventions can still alter Asia's demographic future, the demographic backdrop has been largely set up for the next 20-30 years. The socioeconomic impact and policy implications of this backdrop should be considered carefully in planning for the future. EAFO

Zhongwei Zhao is Professor at the Australian Demographic and Social Research Institute, College of Arts and Social Sciences, the Australian National University.

\section{POPULATIONS IN TRANSITION}

\section{Second dividend holds promise of sustained rewards}

TOMOKO KINUGASA

\section{P} opulation dynamics influence a country's economy significantly through the dividends to economic growth. The first dividend occurs during the demographic transition process, when the working-age population increases as a share of the total population, and the percentage of both young and old dependents decreases. The second demographic dividend results from an increase in adult longevity, which causes individuals to save more in preparation for old age. This increase in savings can thus contribute to capital accumulation and economic growth.

In order to increase

the benefits of the

second demographic

dividend, it is important

to exploit the wealth

accumulated by the older

generation
From the 1960s to 1990s, many Asian countries went through rapid demographic transition. When economic development commences, both fertility and mortality rates are high. As a country develops, mortality rates, especially child mortality rates, decline rapidly. However, fertility rates do not decline at the same time because having many children is conventional and this situation takes a long time to change. So during demographic transition, the population grows rapidly. Later, fertility rates begin to decline rapidly. Once the demographic transition is complete, both fertility and mortality rates are very low, and most developed countries experience population ageing.

In the second half of the 20th century, East Asian countries experienced remarkable economic development in both savings and GDP growth - this was known as the 'East Asian economic miracle'. These countries, especially Japan and Korea, used the first and second demographic dividends during this period. The first demographic dividend offers much potential for growth. There is a large working-age population, so remarkable economic development can be attained by taking advantage of an abundant labour supply. Demographic transition can also increase female labour force participation because the burden of young dependents decreases. 


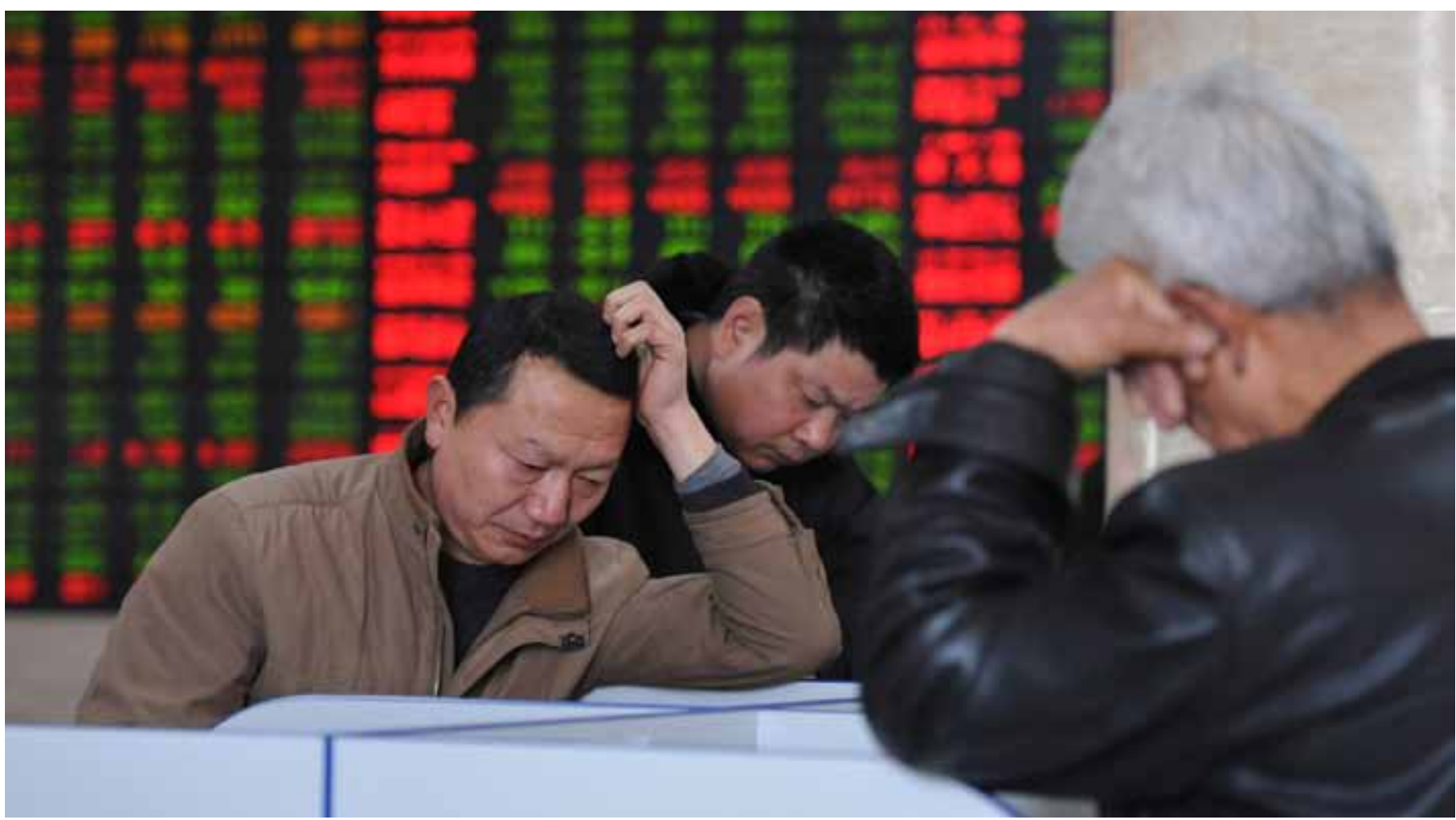

Investors in Fuyang watch the value of their assets ebb and flow as prices fluctuate on the stock market. It is reasonable to suggest that a simple lifecycle hypothesis determines saving: that consumption and savings behaviour is determined according to lifetime incomes.

This working-age population tends to save more than younger and older dependents, in part because it earns more. It is also reasonable to suggest that a simple lifecycle hypothesis determines saving: individuals determine their consumption and savings behaviour according to their lifetime incomes. If individuals know they will retire at a certain age, they save while they are working and withdraw their savings after retirement. In this case, a larger working-age population induces higher national savings, which creates capital accumulation and thus high economic growth.

While the first demographic dividend represents a country's demographic structure, policies to take advantage of this dividend should be encouraged. Even though the workingage population may be large, economic growth would be slow if most were unemployed. Educational attainment and skills also influence how the first demographic dividend affects economic growth. During this period, the country must also keep in mind that the first demographic dividend does not last forever. As it only arises during demographic transition, the country will face an ageing population when it completes this transitional period, and it must prepare for such an eventuality.

The second demographic dividend has been paid only modest scholarly attention, although prominent demographers Professor Andrew Mason and Professor Naohiro Ogawa have emphasised its importance. Many countries must consider utilising it fully. Indeed, adult longevity continues to increase slowly after a country has completed demographic transition. Although some demographers insist that there are binding biological limits to such longevity, remarkable medical developments continue to contribute to increasingly longer lives.

According to the lifecycle hypothesis, an increase in adult longevity increases the savings behaviour of the younger generation. Thus national savings are influenced not only by the level of adult longevity but also by the speed of its increase. If the level of adult longevity is high, the younger generation will have high savings. Theoretically, an increase in the level of adult longevity affects the national saving rate positively if GDP is increasing. The speed of increase in adult longevity will also positively influence the national saving rate, because only the savings made by the younger generation increase.

Most countries have experienced a significant change in the adult mortality rate over time. Yet such mortality transitions in Asian 


\section{EDUCATIONAL ADVANTAGE}

countries are distinctive from those seen in the West. In the West, there were two phases of transition, namely pre-transition and transition. In the pre-transition period, adult longevity was low and stagnant, while it increased steadily in the transition period. In Asia, mortality transition has begun later than in the West. The transition period in Asia has been interrupted by a catch-up period during which adult longevity has increased rapidly. Scholars consider that this rapid increase in adult longevity has contributed to a remarkable increase in savings and GDP in Asian countries.

The second demographic dividend will continue in most Asian countries even after the first demographic dividend has ended. In order to increase the benefits of the second demographic dividend, it is important to exploit the wealth accumulated by the older generation. It is also crucial to educate the older generation in saving money effectively. Moreover, because modern ailments such as obesity are increasing in many developed countries, there is no guarantee that adult longevity will continue to increase perpetually. Enhancing policies to maintain and even increase health and longevity will therefore be necessary.

Asian societies with ageing populations must confront several complex problems, such as a decreasing labour force and an increasing social security burden. However, if Asian countries can develop the second demographic dividend sufficiently, they will have a chance of developing sustainably thereafter. EAFQ

Tomoko Kinugasa is Associate Professor at the Graduate School of Economics, Kobe University.

\section{The Asian century will be built on human capital}

\section{WOLFGANG LUTZ AND SAMIR KC}

A SIA today is home to more than four billion people-more than 60 per cent of the total world population-yet its influence in world affairs remains disproportionately small. The reason for this imbalance is that, while influence on the world stage is partly a function of population size, it also depends on economic and other dimensions. Still, Asia is rapidly catching up in these other dimensions, most importantly in the field of education. While its stunning economic growth-first experienced by the smaller 'Asian Tigers' and now by demographic billionaires China and India-is widely recognised, the extraordinary expansion of human capital, probably the single most important factor behind the region's economic 'miracle', has received much less attention. Almost everywhere in Asia the young are much better educated than the elderly, so further strong improvements in the human

... educational attainment

is closely linked to higher

life expectancy and

economic growth capital of the labour force are inevitable. And those improvements will most likely translate into rapidly increasing economic and political power.

A group of demographers in Vienna at the Wittgenstein Centre for Demography and Global Human Capital-a collaboration between the International Institute for Applied Systems Analysis (IIASA), the Austrian Academy of Sciences and Vienna University of Economics and Business-has recently reconstructed and projected human capital by age and sex for all countries of the world. But what is a country's human capital? The phrase encompasses a population by age and sex, together with its health status and distribution of skills (educational attainment by age and sex). This broad view of population also includes what economists call the 'quality dimension' a factor that can be readily modeled and forecast using tools of multi-dimensional demography.

Compare, for example, the education and age pyramid for China in 1970, as it is now and as it is projected to be in 2050. In addition to the conventional age pyramid that plots women on the right and men on the left, sorted by age group, these figures add colour to show the educational status of men and women in each age group, and their highest levels of attainment. As Figure 1 


\section{Age and education pyramids for China in 1970, 2010 and 2050 under fast expansion scenario.}

FIGURE 1

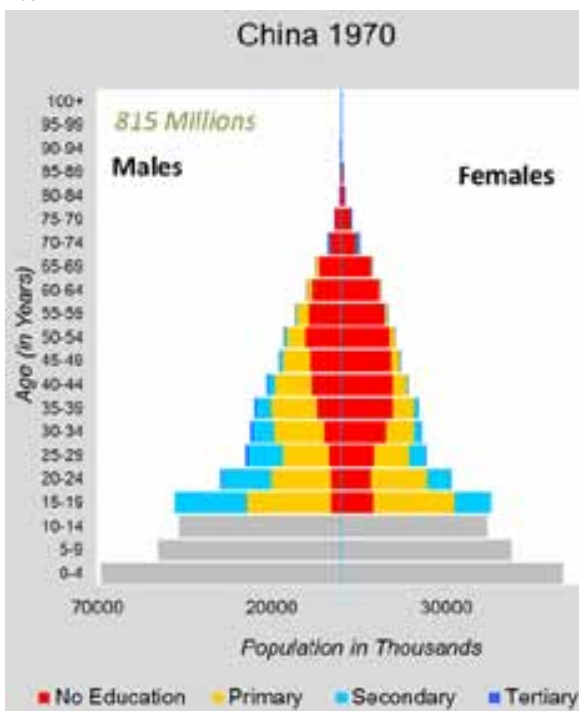

FIGURE 2

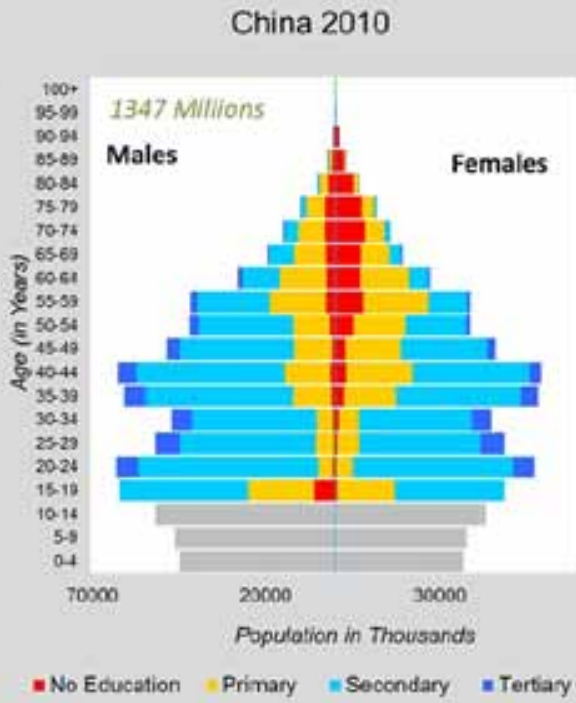

shows, in 1970 the vast majority of Chinese women older than 30 had never received any schooling. It was only in the younger cohorts that an increasing proportion of women had received some primary or even junior secondary education. The figure also shows that for men basic education had already spread. The Chinese picture in 1970 resembles the typical pattern for a poor developing country-such as many African countries today. Figure 2, a snapshot of 2010, clearly illustrates how farreaching the expansion of education has been. A vast majority of each of the younger cohorts in China had completed or were completing secondary education. Still, the legacy of much lower education for the elderly remains. By 2050 the entire age pyramid will be filled with a well-educated population, and China is expected to have a significantly higher human capital base than most industrialised countries today.

This rapid expansion of human capital is likely to have massive consequences for virtually all aspects of society and the economy. It has been shown that a good education has positive effects on human health, wealth and wellbeing. The evidence now clearly shows that educational attainment is closely linked to higher life expectancy and economic growth, and even to the quality of institutions and whether societies will make the transition into modern democracies. While specific predictions are difficult because there are clearly strong path dependencies and cultural factors involved, it is fair to say that as the general population becomes more educated it becomes politically and socially empowered. Recent studies even show that more educated people (after controlling for income) tend to be less vulnerable to natural disasters and hence education may be a key strategy to help societies adapt to unavoidable future climate change.

It's clear from Figure 3 that China has some challenges in store. Due to low fertility the age pyramid gets very narrow at the bottom, and together with increasing life expectancy this implies rapid population ageing. Many other countries in Asia also face this challenge. But consider again the role of education. We know that virtually everywhere the more educated elderly
FIGURE 3

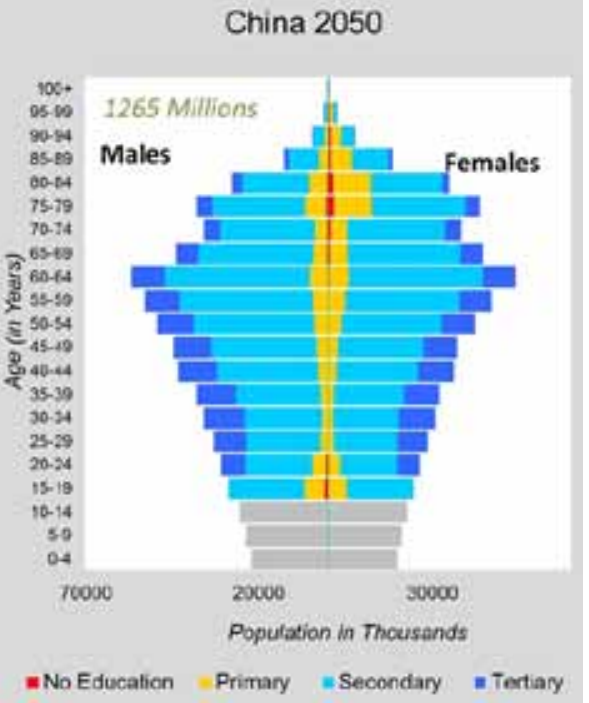

are much healthier than their less educated peers. They also tend to work longer and contribute to society in other ways. Today we say that 70 is the new 60; in the future 80 may well be the new 70. At the same time, at the bottom of the pyramid it may be that a smaller number of highly educated young people is exactly what the labour markets of the future need, as production becomes more and more automated and technology advances. If this turns out to be the case, low fertility in Asia may not be an obstacle to making the 21st century the Asian Century. It could even be an advantage, as it will make it possible to invest even more into making people skillful, healthy and knowledgeableenhancing the wellbeing of everybody.

EAFQ

Wolfgang Lutz is Founding Director of the Wittgenstein Centre for Demography and Global Human Capital, International Institute for Applied Systems Analysis, Vienna.

Samir KC is a Research Scholar at the International Institute for Applied Systems Analysis, Vienna. 


\section{Demographic dividends: a window of opportunity}

BHAKTA B. GUBHAJU

N 2010, a dominant share of the world's nearly seven billion people-4.2 billion, or 60.4 per centlived in Asia. Of those, 1.7 billion lived in South Asia, a number that is projected to increase to 2.4 billion by 2050.

This increase will partially reflect demographic transition within the South Asian region. This has been the result of at least two key trendsdeclining fertility rates and improved life expectancy.
Fertility transition in South Asia began over 40 years ago, falling from a rate of around six children per woman in the late 1960 s to reach three at the beginning of the millennium. The striking thing about the fertility transition in South Asia is the speed at which some countries have experienced the decline: fertility has fallen below the replacement level of 2.1 in Iran and the Maldives, and is close to the replacement level in Bhutan, Bangladesh, India, Nepal and Sri Lanka.

Declining fertility rates have been accompanied by a remarkable improvement in life expectancy at birth. A child born today in South Asia can expect to live on average 65 years, up from 42 years five decades ago. Countries that have achieved an average life expectancy of more than 70 years include Iran, Sri Lanka and the Maldives, while at the other extreme is Afghanistan, with an expected lifespan of less than 50 years.

This combination of declining fertility and increased longevity has resulted in population ageing, an issue that is challenging several countries

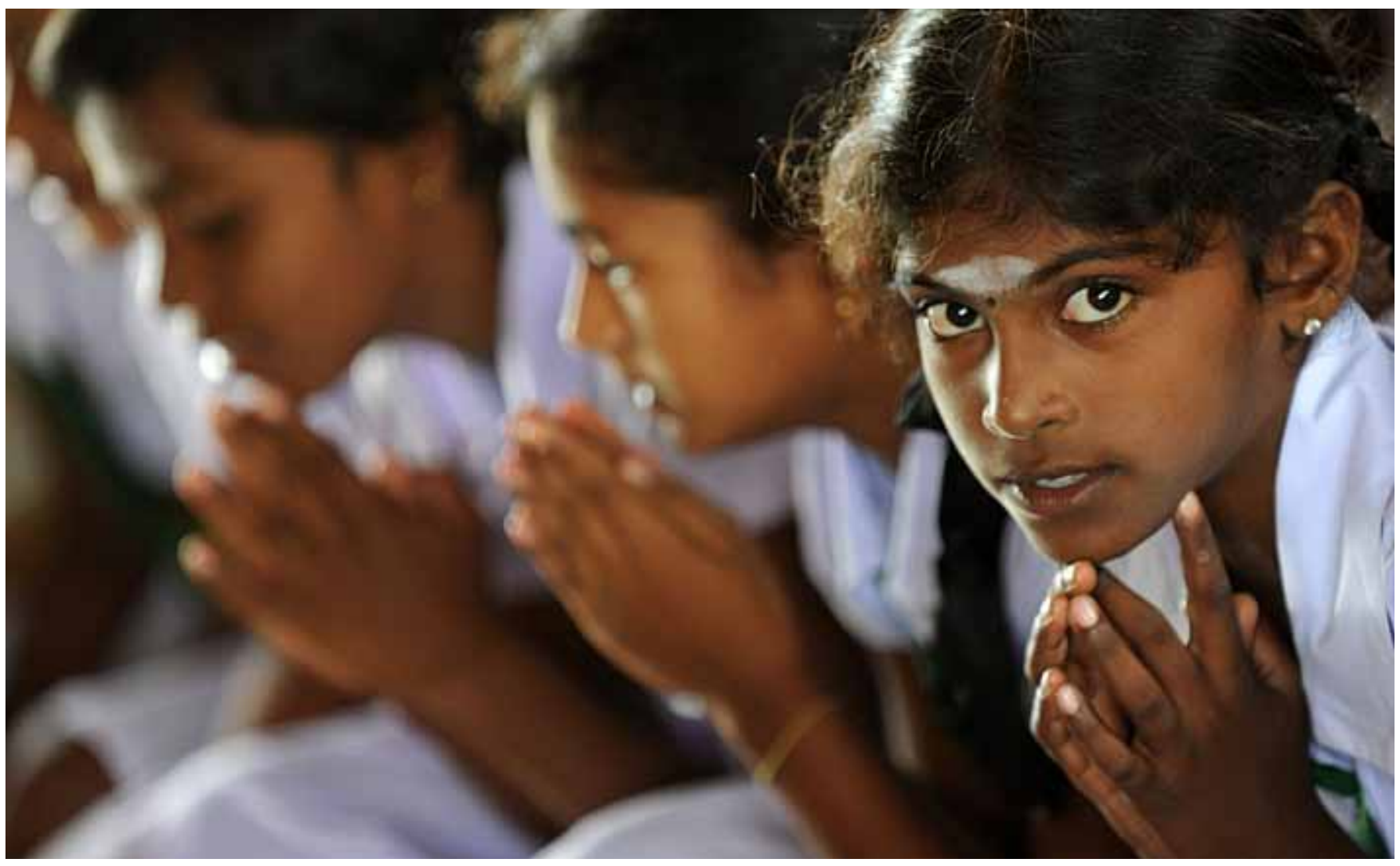

Tamil schoolchildren praying at a school in Sri Lanka. A child born on the island state today can expect to live on average 65 years.

PICTURE: ISHARA S. KODIKARA / AFP PHOTO / AAP 
in Asia, including some in South Asia. In the past six decades, South Asia's 60-plus population has increased four-fold, from 28 million in 1950 to 125 million in 2010. Percentage-wise, this age cohort number is projected to increase from 7.3 per cent of the total population to reach 10.5 per cent in 2025, and 19.1 per cent in 2050.

Population ageing and the associated growth in the size of elderly populations have a number of troubling policy implications. In many Asian countries, particularly those in South Asia, the healthcare infrastructure is already weak. Most of its resources are taken up with providing mother and child health services and reproductive health services such as family planning. The medical, public health, social services and other facilities required to meet the needs of the elderly are therefore likely to put severe strain on the healthcare system and the economy. Also, given that old age is a major risk factor of non-communicable diseases such as cardiovascular conditions, cancer and diabetes, population ageing will sharply increase the need for longterm health care. Non-communicable diseases account for nearly threefifths of deaths, and are associated with high costs of treatment and care. Counterbalancing these costs will require a greater emphasis on disease prevention and screening for early detection.

Another challenge is that a majority of countries in Asia do not have social security systems. Countries that do will still face problems in caring for the elderly population. Day-to-day care of the elderly requires a great many resources, including assistance from family members. The care needs of elderly women, in particular, will put extra pressure on family members. This is because in many countries,
South Asia has yet to

put in place the

appropriate social and

economic policies that

are needed to fully

capitalise on the

demographic dividend

women are less educated and have had less formal work experience than men, as well as having lower income, fewer assets and less authority within the family. Women are therefore more likely to be dependent on family members and public programs, especially at advanced ages and when they are ill or disabled. The burden of care-giving will also usually fall on women, who are then caught up with a multitude of responsibilities, such as raising children, caring for elderly parents and engaging in economic activities-forming what is known as the 'sandwich generation.' Governments should provide more intensive and practical support to this group of caregivers to ensure that the elderly receive the support they need.

Nonetheless, demographic

transition in South Asia is still continuing. The share of the workingage population will continue to grow in almost all South Asian countries for another two or three decades. This suggests that there is potential for continued economic growth. Since the 1970s, all subregions of Asia have experienced significant increases in their working-age populations during various stages of demographic transition. This growth of a workingage population that has fewer dependent children and elderly to support is known as the 'demographic dividend' because it provides a window of opportunity to build human capital. The benefit it affords lasts for four to seven decades. The demographic dividend has been most pronounced in East Asia, where the working-age population peaked at 72 per cent in 2010 before declining rapidly. Studies suggest that it accounted for between one-fourth and two-fifths of East Asia's spectacular economic growth. Southeast Asia is also currently reaping the benefits of a demographic dividend, which will likely be reduced over the next two decades as its population ages.

But South Asia has yet to put in place the appropriate social and economic policies that are needed to fully capitalise on the demographic dividend. Effective policies in key areas such as population and family planning, public health, education, governance and economic management will allow maximum returns, particularly from the working-age population. Policymakers and planners must be aware of the demographic dividend's relevance to investment planning and human resources development. The demographic dividend is a unique window of opportunity that South Asian countries must not miss. The region must prepare itself for the irreversible demographic transition that will follow. EAFQ

\section{Bhakta B. Gubhaju is Adjunct} Associate Professor at the Australian Demographic and Social Research Institute, Australian National University. 


\section{Ageing societies involved in a race against time}

\section{RAFAL CHOMIK AND JOHN PIGGOTT}

N THE next 30 years an additional one billion people will call Asia home. But the expansion of Asia's population and its economic power will take place in the context of another very dramatic demographic change: its population is ageing, and fast.

Some countries, such as Japan, already have an elderly population that makes up a larger proportion of total population than at any time in their past. Others, such as China, are still young but ageing faster than many advanced economies, including Australia and the United States. The changes have been a long time in the making. But recently China's Vice Premier, Hui Liangyu, publicly said that the scale and speed at which the population was ageing had exceeded expectations, and that 'China has not adequately prepared to respond to the ageing population'
What does Asia's demographic transition mean in economic terms? And what policies, institutions, and economic structures can Asia put in place to respond and take advantage of the changes? In particular, Asian societies will have to find an effective way to transfer economic resources between and within generations, ensuring adequate retirement incomes for the old.

Reforms to the way retirement income and healthcare are provided

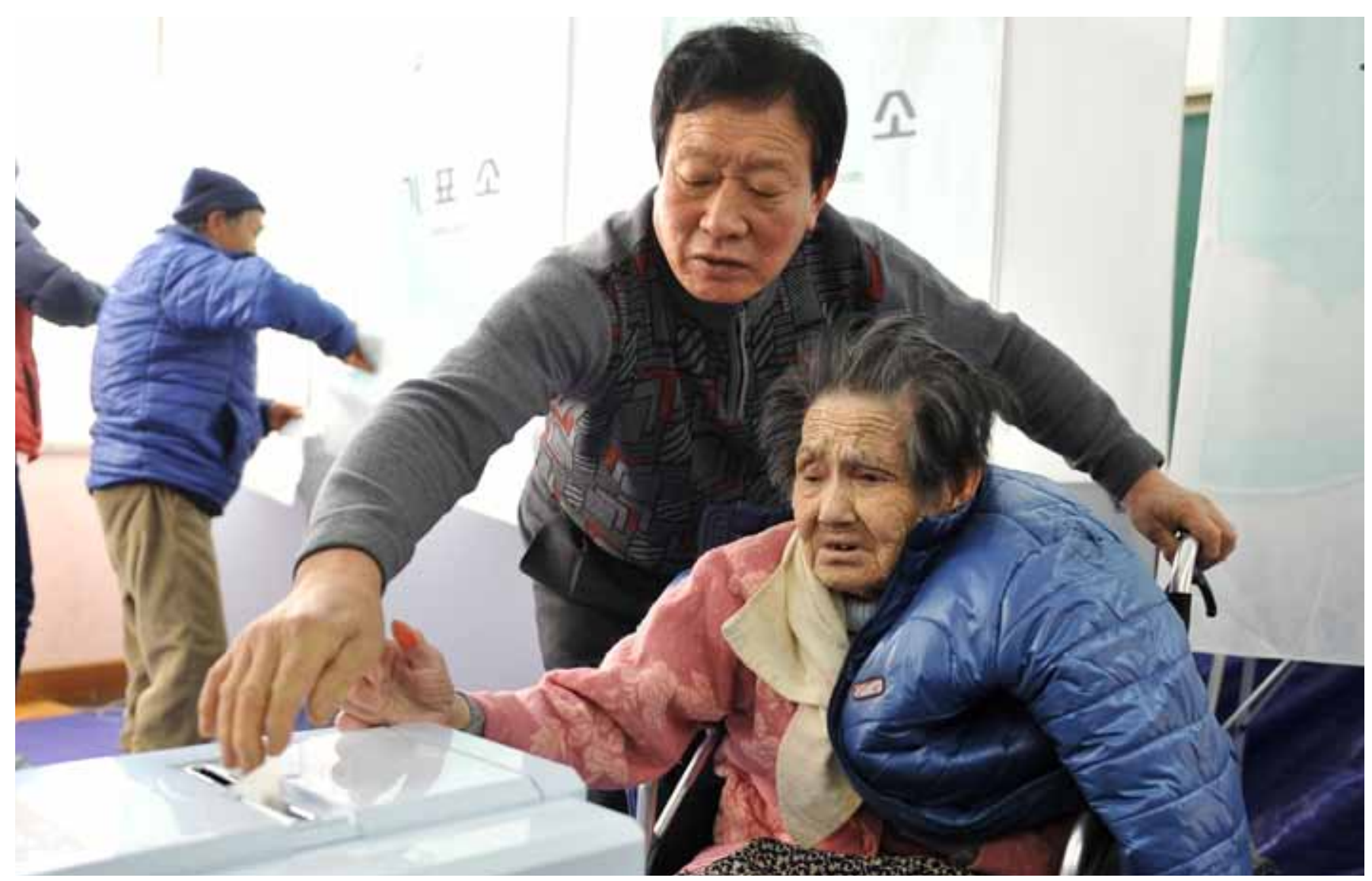

An elderly woman at Nonsan is helped to cast her vote in South Korea's presidential election in December 2012. South Korea is among those Asian countries whose populations are ageing most rapidly. 
represent a macroeconomic opportunity to rebalance growth across Asia-a chance to allow individuals to pool risks associated with income and health shocks and to reduce the need for households to have excessive precautionary savings.

The scale of the challenge differs according to the timing and speed of the transition. Countries that are ageing fastest include Japan, Korea and Singapore, whose age-dependency ratio-the proportion of older people (65-plus) to working-age people (15-64) - will be between 58 and 70 per cent by 2050 . For Singapore, this means more than a quadrupling of the dependency ratio from 14 to 58 per cent in less than two generations.

China and Thailand, with a projected age-dependency ratio of over 40 per cent in 2050, will have an age structure that is older than those we expect to see in Australia and the United States. At the other extreme are countries such as India, the Philippines and Pakistan, which will have an age-dependency ratio well below the current OECD average of 27 per cent in 2050, despite some ageing.

Population ageing is driven by increases in life expectancy and decreases in fertility, two factors that have contributed to rising economic growth across Asia in the past two decades. In the period preceding population ageing, large numbers of working-age people, unencumbered by the need to look after large numbers of children or the elderly and leading longer, healthier lives, were free to participate in the labour market. This phenomenon has come to be known as the 'demographic dividend'. Estimates vary, but some analysts have calculated that the demographic dividend may have accounted for between one-quarter to one-third of high growth rates in the 'East Asian miracle'. The large number of workingage people relative to the total population provides an opportunity to set up policies, institutions, and economic structures that will be favourable in the final stages of demographic shift.

Most advanced economies have already experienced their peak and are now seeing their working-age population fall. The proportion of the working-age population within Australia has started its decline but the number of working-age people is still increasing in absolute terms. In Japan the fall is both relative and absolutethe proportion and number of the working-age population is decreasing. The decline in available workers in OECD countries has been softened, however, because women have been joining the labour force, a trend which has actually caused ratios of employment to population to increase.

A large proportion of Asian countries are currently at the top of the working-age population hump. For them, the window of opportunity to prepare for an older population will close within the next decade. Thereafter population ageing is likely to hold back economic growthsomething the Chinese government is acutely aware of, referring to

The private sector ...

could invest in the

capacity to provide

financial services that

will help transition Asian

workers into retirement population ageing explicitly when it lowered China's GDP growth target in 2012 to a seven-year low of 7.5 per cent. Future growth will rely more heavily on higher productivity as urbanisation drives farmers to factories, and as technology and education raise the efficiency of existing urban (and rural) workers.

A key difference between advanced countries and the emerging Asian nations, and one that makes it all the more important to capitalise on the demographic dividend, is that the speed of Asia's demographic transition means that many countries risk growing old before getting rich.

So how can Asian countries take advantage of this window of opportunity? They can start by reforming retirement income provision systems, especially given the retreat of family support. In this regard, four key lessons can be learned from the mistakes and successes of advanced economies.

The first relates to the structure and generosity of the retirement income system. Many Asian countries have a pension system that revolves around defined benefit schemes. These pay earnings-related pensions and were once popular in Europe, where they have resulted in unfunded liabilities with a worsening ratio of pension recipients to contributors. To remain solvent, they require features that account for demography (such as those implemented in Germany or Sweden). China's generous urban worker's scheme will need similar reform. It is only affordable now because it is not yet mature or widespread.

Second, how and when people can access pensions will affect both schemes' affordability and incentives to work. The demographic dividend experienced by OECD countries in the late 20th century meant that for 
a period of time pension systems became more generous and allowed people to retire much earlier than they had in the past or will be able to in the future. There has been much backpedalling, and pension ages have been increasing across the OECD since the late 1990s. Official pension access ages are relatively low in Asian countries outside the OECD: on average 59 for men and 57 for women. This is low even adjusting for lower life expectancies.

Third, an adequate pension level should not be sacrificed in the pursuit of financial sustainability. Large proportions of Asian populations are not covered by pensions-not surprising given the region's stage of development. But as regional urbanisation dilutes intergenerational ties, and longevity increases, countries will need to expand pension coverage to a greater proportion of the population at much lower levels of GDP per capita than were enjoyed in the West. This is a particular problem for social pensions that focus on the poor.

Finally, an adequate pension should amount to a regular income in retirement. Purchasing an annuity product, as opposed to spending a lump sum, can insure the purchaser against longevity, investment and inflation risk. The mandatory saving systems that do exist in the region often only offer lump sums, with few options to purchase an annuity. This challenge also exists in developed countries in the region such as Hong Kong, Australia and until recently, Singapore, where the government has recently stepped into the market.

The private sector, too, can benefit by paying attention to demographic trends. It could invest in the capacity to provide financial services that will help transition Asian workers into

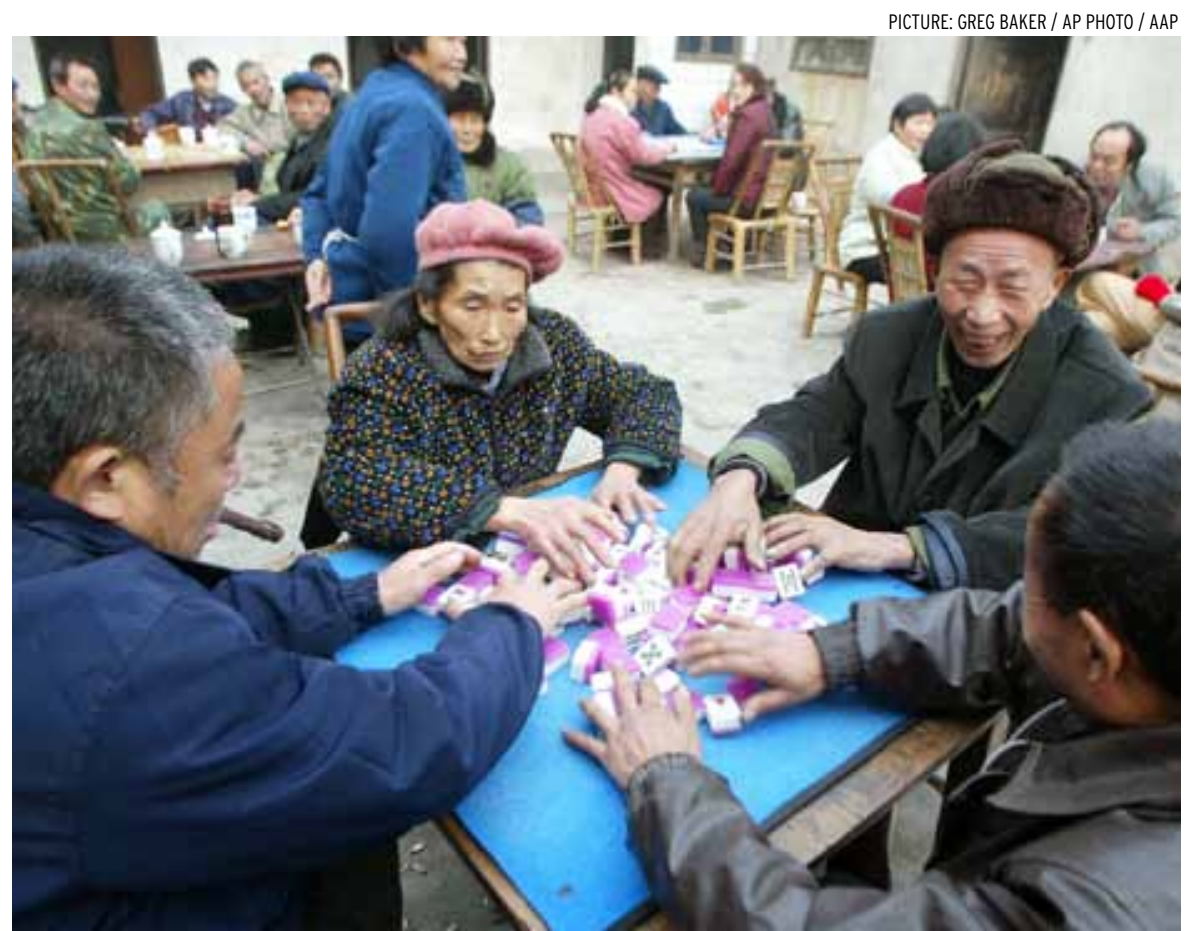

Elderly Chinese mahjong players shuffle the tiles in Chengdu. As urbanisation and longevity increase across Asia, an adequate pension should amount to a regular income in retirement.

retirement, much as has happened with assets built up by baby boomers in the OECD. Total pension assets in the Asia-Pacific (excluding Australia, New Zealand, and Japan) were worth nearly US $\$ 500$ billion in 2011, and continue to grow.

But well-functioning private pension markets require certain preconditions relating to regulation, incentives, cost structures, market depth and flexibility, and workforce skills. Here, experts from countries such as Japan and Australia may have a competitive advantage to contribute to the development of the region's pension and insurance system.

Both have extensive experience in population ageing research and policy implementation. They have the largest pools of pension assets under management in the region and worldclass financial expertise. Australia's financial and insurance industry is as large as its mining industry, but it exports very little and it is only now that some institutions are beginning to open foreign offices in the region.

Superlatives about Asia's economic miracle abound. These will now expand to include the speed and scale of the region's population ageing. What we are realising is that the Asian century will also be a grey one-an important concept to grasp for countries, institutions, and individuals wishing to understand their place in its future. EAFO

Rafal Chomik is Senior Research Fellow at the ARC Centre of Excellence in Population Ageing Research (CEPAR), at the University of New South Wales.

John Piggott is Director of CEPAR, and Scientia Professor of Economics at the University of New South Wales.

This article is based on a series of CEPAR research briefings on 'Asia in the Ageing Century', for the Centre of Excellence in Population Ageing Research (CEPAR). 


\section{Asia's silver revolution}

\section{HEATHER BOOTH}

N EVER before has population ageing occurred on anything like the scale now being experienced. Japan is at the forefront of this revolution and many other Asian countries are set to follow. In the space of a single lifetime populations have been transformed and family structures turned upside down. No longer do grandparents count grandchildren on fingers and toes; today, four grandparents may beget but a single grandchild.

How did this 'silver revolution' occur? Of the multiple demographic drivers of population ageing, fertility decline is most potent. With smaller numbers of children in the population, the proportion of the population who are elderly will increase, and will increase even more if the elderly also live longer. Japan holds the record in population ageing because post-war fertility declined dramatically and longevity has increased rapidly. It is the timing and rapidity of demographic change that places Japan's population ageing ahead of other developed countries which underwent a more gradual demographic transition.

Significant economic and social transitions underlie and accompany ageing's demographic drivers. Countries that have undergone substantial post-war economic development are cases in point-in 2012, the percentage of people 60 and older in Japan stood at 32 per cent; in Hong Kong at 19 per cent; in South Korea at 17 per cent; and in Singapore at 15 per cent. Effective population policies, such as China's one-child policy and Vietnam's intermittent two-child policy, have accelerated ageing in countries not yet sufficiently industrialised for spontaneous fertility decline to occur. By 2050, according to UN projections, Japan's 60 -plus proportion will exceed 40 per cent, and many other countries in Asia will exceed 30 per cent. What is more, high proportions at older ages will remain the norm.

The much-heralded economic problems of population ageing are becoming increasingly evident to governments and individuals alike. High old-age dependency ratios place a substantial burden on the workingage population, whether through taxation or familial support. At the same time, pressures to save for one's own retirement and eventual care are rising, fuelled by expectations of both a longer life and a lack of family support. The silver revolution involves all generations.

To provide for increasing numbers of senior citizens, governments seek to raise additional revenue by encouraging greater labour force participation and increasing the retirement age. The latter has the added benefit of reducing aged pension costs. Singapore is increasing the statutory retirement age from 62 years to 65 and later to 67 . Korea is considering an increase from 57 to 60, and China an increase from 60 for males and 50/55 for females to 65 for all. Such measures, however, are not efficacious where participation is already high or mostly in the informal sector, or where state provision of aged pensions has yet to emerge. In
India, for example, the formal sector is relatively small and few elderly males (and even fewer females) have pension rights, maintaining high participation rates in the informal sector well into old age. In Japan, where employees already work well beyond the statutory retirement age of 60 , negating the value of any increase, a gradual doubling of the 5 per cent sales tax has recently been introduced to cover the costs of ageing.

W HILE Japan's wealth provides the means to weather the problems of population ageing, many other countries in Asia are not so well placed. Growing old before getting rich is not an enviable situation.

China, for example, faces a considerable burden. Her remarkable achievements in curbing population growth-which not only benefitted her own economic development but the ultimate sustainability of the planethave resulted in rapid population ageing. The proportion aged 60-plus is set to increase from 13 per cent in 2012 to 24 per cent in 2033, when the population will reach its peak, to 34 per cent in 2050. Despite high rates of economic growth, population ageing presents China with a formidable challenge, not only because of the sheer size of the older population but also because of ongoing developmental changes in Chinese society. The ability of working-age people to provide informal care for elderly parents has been eroded by several factors, including fewer multigenerational households, increasing labour migration and the pressures of highly-formalised work routines and 


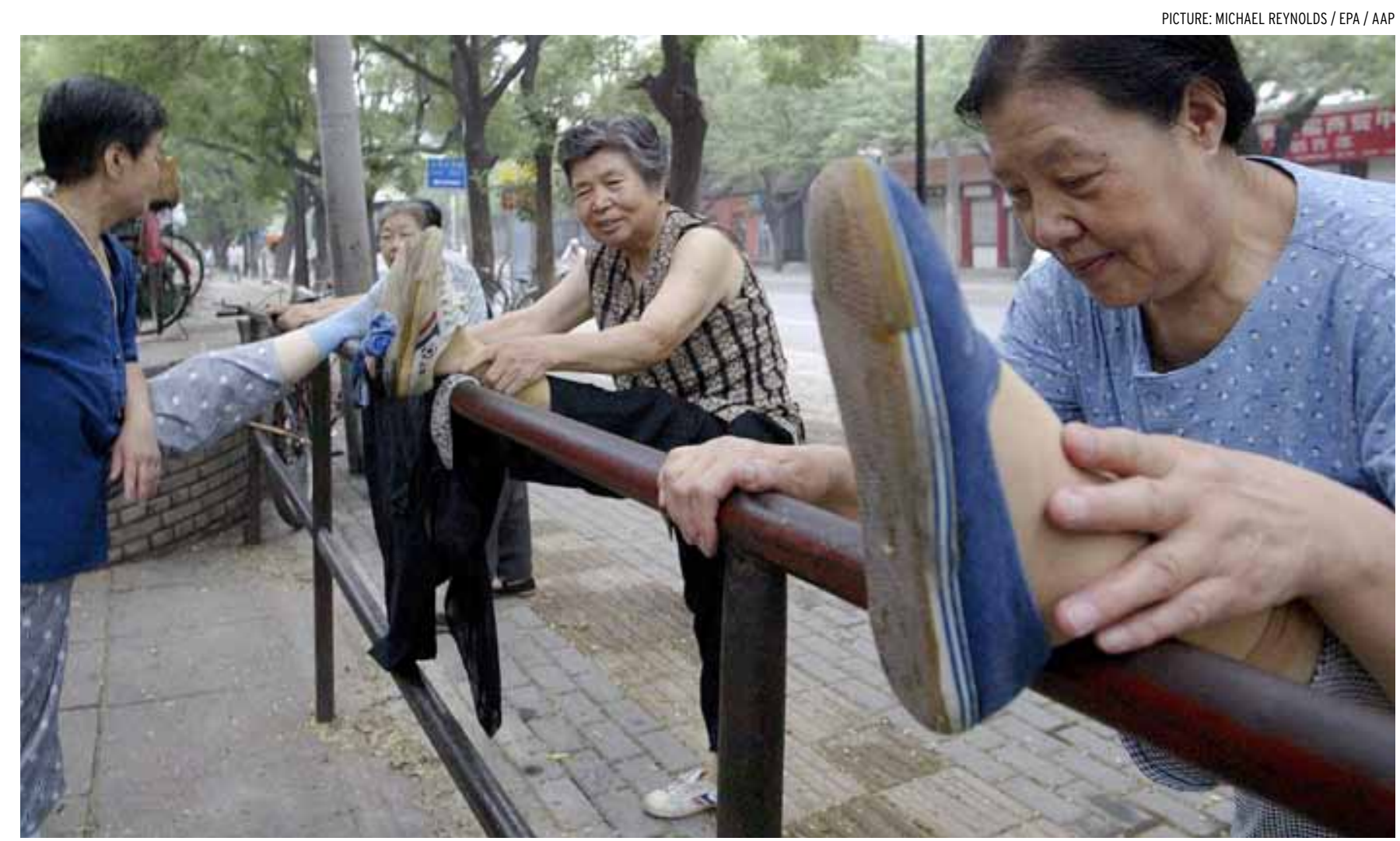

Working out in a Beijing park: the proportion of Chinese aged 60 or over is expected to reach 24 per cent of the population by 2033.

professional competitiveness. This situation is compounded by the 4-21 problem, whereby the only child becomes responsible for two ageing parents and four grandparents (the prospect of an 8-4-2-1 problem is already on the horizon), leading to hardship for increasing numbers of the elderly and those who support them. Though China's 12th Five-Year Plan includes the establishment of a basic aged care system, its adequacy is in question in terms not only of coverage but level of care. The main burden of support and care will continue to fall on the family.

The problems of population ageing are shared to varying degrees by most, if not all, developing countries in Asia. While government provision is inadequate, the private and nongovernment market for goods and services has yet to emerge beyond a token presence. Private aged care fees are prohibitive, even among the middle classes, retarding development of the market. Moreover, shortages of trained staff keep the supply of aged care low-and the price high. With many private facilities resembling five-star hotels, there is clearly room for more affordable facilities to be developed under not-for-profit business models or government subsidisation.

H IGH old-age dependency ratios and changing socio-economic circumstances threaten the viability of the centuries-old 'intergenerational contract' whereby successive generations care for their elders. As a generation, the elderly are losing status as education and materialism gain sway. The ways of the past are rapidly devalued in the scramble for wealth, even though personal respect may endure. The pressures of the modern economy and the new demographic reality lead at times to desperate responses, including elder abuse, the abandonment of elders by migrant family members, or suicide by older people who perceive themselves to be a burden.

The silver revolution is unprecedented, and once completed will not occur again. It brings a new balance between the generations and, nuanced by cultural influences, involves profound and widereaching social change. Only careful management of its consequences will deliver a healthy and wealthy postrevolution society. Today's younger generations might take a moment to consider what kind of society they are looking forward to in old age. EAFQ

\section{Heather Booth is Associate Professor, Australian Demographic and Social Research Institute, the Australian National University.}




\section{China facing a declining working-age population}

YI ZENG, JOHN KNIGHT

AND ZAI LIANG

EAFQ: How will the age structure

of China's population change over the coming decades?

Yi Zeng: The very large size of China's elderly population and its rapid increase as a proportion of the total population are both unique characteristics of population ageing in China. In 2010 there were 119 million Chinese aged 65 and over, constituting 8.9 per cent of China's total population. Under a medium-fertility outlook, based on a two-child policy, and medium mortality assumptions, it is projected that there will be 363 million elderly Chinese by 2050 -or 25.9 per cent of the total population.

The average proportion of elderly households-with at least one person aged 65 or over-will increase dramatically in China over the next few decades. And by the years 2030 and 2050, respectively, the average proportion of elderly households living without children will be 2.5 and 3.7 times higher than in the year 2000. The percentage of Chinese aged 80 and over living in empty-nest households will be even more dramatic: 4.0 and 11.5 times higher than in the year 2000 for the years 2030 and 2050.

The challenges of an ageing population will be much more serious under a low-fertility scenario-leaving the current fertility policy unchanged-than under a medium-fertility scenario which would introduce a two-child policy. Moreover, if the majority of ruralurban migrants continue to be young Chinese citizens, as observed in the recent census, these challenges will be much more serious in rural China than in urban areas. The central region will face the biggest problems, followed by the eastern region.

\section{EAFQ: How can China be expected} to overcome the challenge of an ageing population?

Yi Zeng: While population ageing presents a serious challenge-because China will be old before it is rich-it could also present an opportunity if

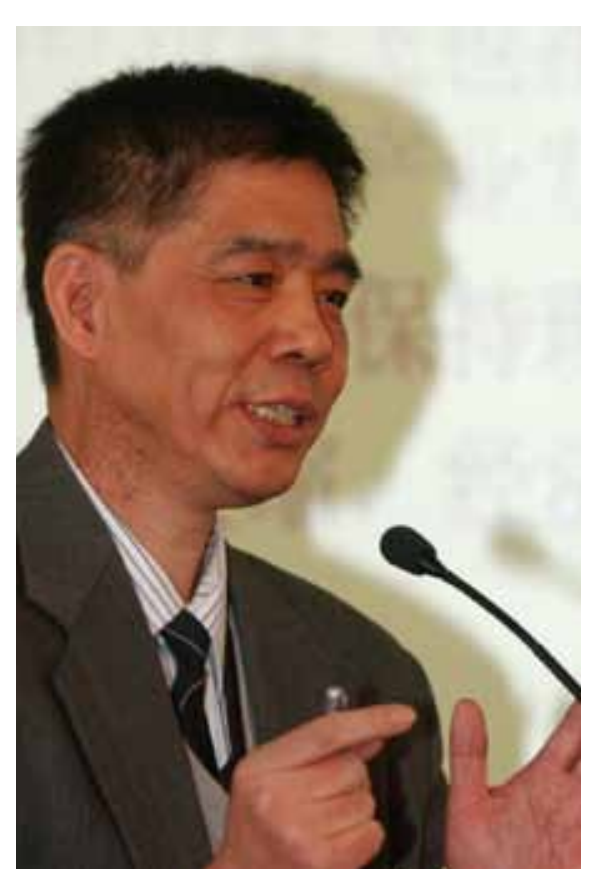

Yi Zeng: China needs a smooth and quick transition to a universal two-child policy and a gradual increase in the retirement age. sound policies based on deep scientific research are implemented. China's population ageing could produce huge new markets and greater employment in services and products for the elderly. Consumption is also expected to increase over time, which may bring new opportunities for continued economic growth if the right policies are developed.

If a two-child policy is implemented soon and the average age of retirement gradually increases from the current very low level of 60 for men and 55 for women to 65 years for both men and women by 2050 , the annual pension deficit rate would be largely reduced or eliminated. With everything else being equal, the annual pension deficit rate under the medium-fertility (two-child policy) scenario would be much lower than under the low-fertility (current fertility policy unchanged) scenario after 2030. China needs a smooth and quick transition to a universal twochild policy, and a gradual increase in the retirement age.

China also needs to change its household registration policy, which restricts free family migration. And it needs to adopt new policies to encourage family migration, including older parents moving from rural to urban areas and among eastern, central and western regions, in order to avoid disproportionate ageing in China's rural areas and in the central region.

EAFQ: How is China's ageing population affecting its labour force? 


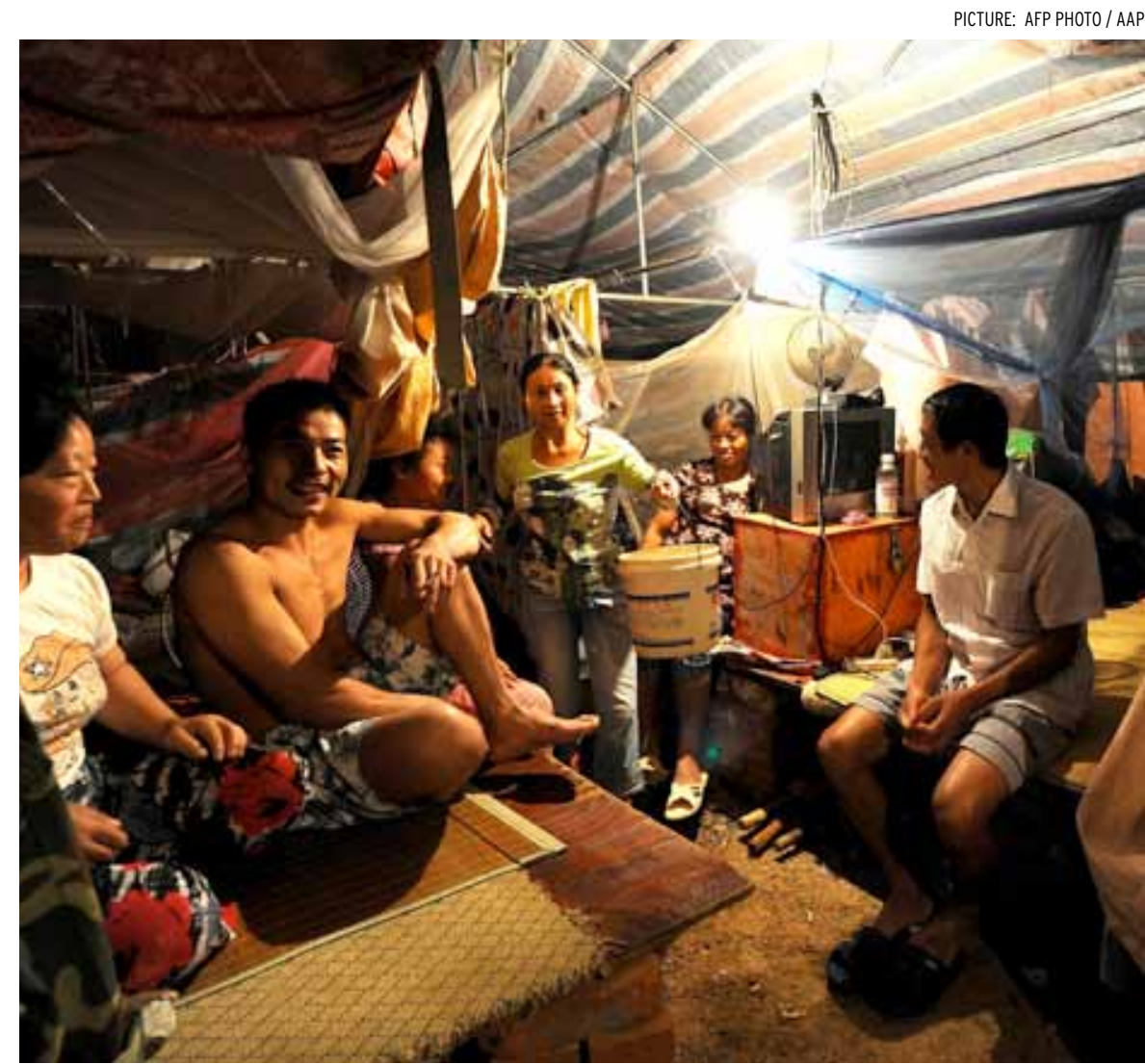

Migrant workers resting in their makeshift tents near a construction site in Hefei, in Anhui province, eastern China. Workers such as these have 'contributed enormously to China's economic miracle in the past three decades as they built China's skyscrapers and laboured in China's factories'.

John Knight: China's labour force is declining, or will be very shortly. The urban-born labour force will fall by 6.4 per cent over the 15 years between 2005 and 2020, with the fall starting in about 2010 and accelerating in the following years. The rural-born labour force will rise by only 2.6 per cent over these 15 years, but the rise will be confined to the first five years and there will be a fall in the last five.

The reason for the decline is the one-child family policy that began in the late 1970s. However, the impact of the policy on the labour force was delayed by an 'echo baby boom': Mao's exhortations produced a baby boom in the 1960s and early 1970s, which in turn produced a bumper crop of couples of child-bearing age two decades later. But recently there has been a violent demographic swing. If the number of urban children aged $15-19$ is 100 , in 2005 the number of urban children in the age groups 15-19, 10-14, 5-9 and 0-4 decreased in the proportions 100, 81, 66 and 56 respectively; the rural pattern was similar although not so dramatic, being 100, 104, 79 and 68, respectively.

\section{EAFQ: How will China's declining} labour force affect its economic prospects?

John Knight: The implications for the Chinese economy and society will be dramatic. If China's economy continues to grow as rapidly as it has done over the period of economic reform, the urban demand for rural workers will soar. On conservative assumptions rural-urban migrants will constitute two-thirds of the urban labour force in 2020.

There is a lively but unsettled debate about whether China has reached the 'Lewis turning point', that is, whether the previous abundance of unskilled labour which has fuelled China's rapid economic growth has come to an end and whether there is now a growing scarcity of unskilled labour. The issue has drastic implications for income inequality and for industrial strategy. It would seem the Lewis turning stage (stage is more accurate than point) is very likely to take place in the second decade of the 21 st century.

Zai Liang: China is capturing a lot of mass media headlines these days. Here are two news-making events since 2010. First, China's level of urbanisation exceeded 50 per cent in 2011. Second, the data from the 2010 Chinese population census show China's floating population (loosely defined as migrants who do not possess local household registration) reached 221 million in 2010, another new record. In fact, the two statistics are closely related: the rise of migration and China's floating population have overwhelmingly contributed to China's rising level of urbanisation and urban growth. These migrant workers also contributed enormously to China's economic miracle in the past three decades as they built China's skyscrapers and laboured in China's factories supplying goods across the globe.

\section{EAFQ: How can China better} support its labour force and migrant workers in the future?

John Knight: At present migrants are second-class citizens in the cities, 
and the many impediments to urban settlement help to maintain the system of temporary migration from the villages. As migrants move up the job ladder to fill vacancies, the economic and social pressures for them to be allowed to settle permanently in the cities will grow. The migrants will become proletarians.

Zai Liang: If the past policy on migration can be characterised as 'open the city gate for rural migrants', the focus for any new policy should be on how to accommodate these newcomers to the city. This does not mean that migrants should be given special favours or privileges, just the right to be treated equally to other urban residents. Even this is not going to be easy, especially for a country with a long history of governance under a rigid and discriminatory hukou (household regulation) system.

Things have clearly improved for the floating population. Gone are the days when many major Chinese cities reserved certain occupations for city residents only. Gone are the days when the floating population was portrayed as blindly floating everywhere. In fact, the rhetoric is very much in favour of accepting the newcomers as deserving the same rights as other urban residents. Still lacking are concrete steps and policies that will benefit and improve the life chances of the floating population and their families: education of migrant children, health benefits and housing, to mention a few.

\section{EAFQ: How could education in} particular be improved for migrant children?

Zai Liang: One hot topic these days is this: are migrant children allowed to take national college entrance exams in their migrant destinations,

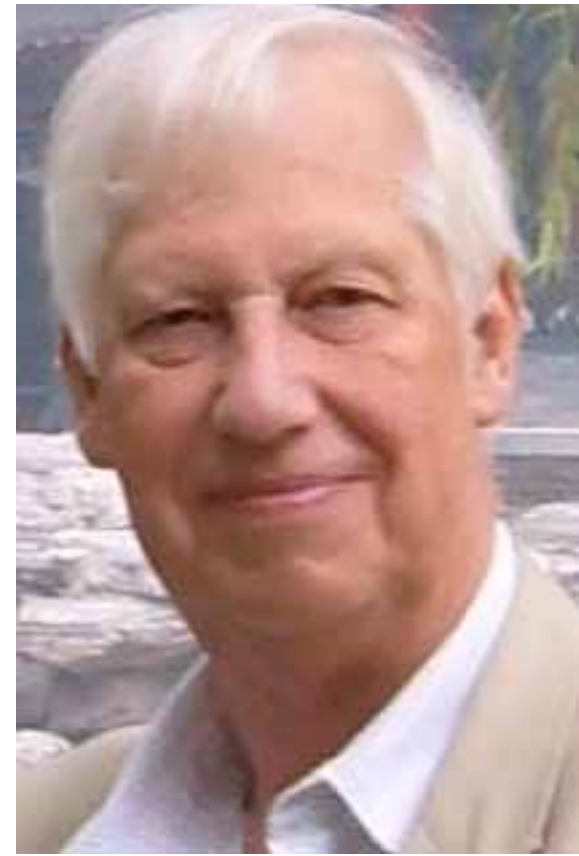

John Knight: Urban demand for rural workers will soar if China's development continues to grow as rapidly as it has in recent decades.

such as Beijing or Shanghai? The question may seem very simple, but it challenges the fundamental principles of who deserves what among urban residents and newcomers. Take the case of Beijing, for example. The children of Beijing hukou residents right now enjoy the advantage of attending elite colleges or colleges in China simply because they have Beijing hukou and take their college entrance examination in Beijing. Now the migrant children (many of them have lived in Beijing for a long time, some were even born in Beijing) are fighting for their right to do the same. At the request of China's Ministry of Education, all provincial governments announced policies on this issue by the end of 2012. The outcome is clearly not satisfactory for migrant children who plan to go to college in 2013. Significant barriers will exist for the next few years at least.

There has been a lot of talk about 'the Chinese dream' in the media

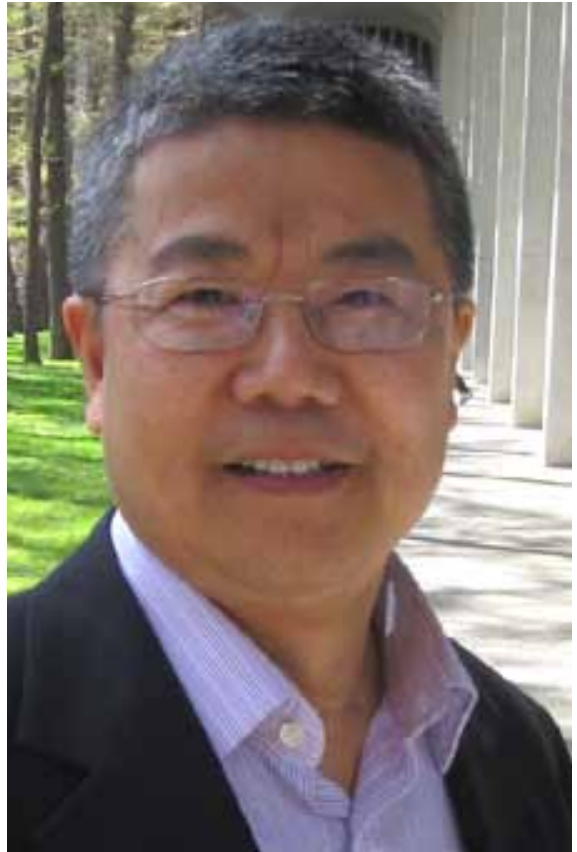

Zai Liang: The rise of migration and China's floating population have overwhelmingly contributed to the rising level of urbanisation.

lately, but a real Chinese dream must ensure China's urban newcomers have equality of educational opportunity, including the right to take national college entrance exams in the city they call home. EAFQ

\section{Yi Zeng is Professor at the Center} for the Study of Aging and Human Development and Geriatric Division, Duke University. He is also Professor at the Center for Healthy Aging and Development Studies, National School of Development, Peking University.

\section{John Knight is Emeritus Professor of} Economics at the University of Oxford. The research on which these comments are based can be found in John Knight and Sai Ding, China's Remarkable Economic Growth, Oxford University Press, 2012.

Zai Liang is Professor of Sociology at the University of Albany, State University of New York. 


\section{Asia's consuming classes and the environment}

ADRIAN C. HAYES

T HE SHIFT to urban living in Asia is unprecedented in speed and scale. United Nations projections suggest that in China alone the urban population will grow by more than 390 million during the first two decades of this century, a figure greater than the current population of the United States, Canada and Australia combined.

This urban shift is lifting tens of millions of people out of poverty and producing a large population of consumers with money to spend on goods and services beyond basic necessities. It has been calculated that when the United Kingdom began to industrialise in the 18th century it took more than 150 years for GDP per capita to double; the United States and Germany achieved a similar doubling in the 19th century in 53 and 65 years, respectively; and in the early 20th century Japan took only 33 years. At the close of last century China had doubled its GDP per capita in just 12 years while India, starting a little later, did it in 16. Asia's population is becoming more urban, and its cities are increasingly dominated by a rapidly growing class of consumers. How these new consuming classes decide to spend their money will have major consequences for local and global economies, culture, politics, and - not least - for the environment.

Income and what is available in the market are now the only tangible limits on consumer choice in Asia.
But in reality the choices people make when they buy are influenced by the cultural and symbolic properties of the item chosen. The status of an item is often just as important as-or even more important than-its physical or sensory properties. For example, drinking coffee in a Starbucks in Shanghai says more about the consumer than the fact that they are simply thirsty. It also establishes their place in a social world and projects for them a shorthand 'identity'. This kind of behaviour is taking Asian economies by storm as millions more every year enter the ranks of the consuming classes. Some Western economists believe sustaining this growth of demand in Asia is key to overcoming the effects of the current global financial crisis. In any event, what people choose to buy today helps to determine what tomorrow's society will look like, so understanding Asian societies demands that we examine how cultural, political, community and market forces (including the international media and the internet) inform their consumers' behaviour.

$\mathbf{T}$ HE rise of the consuming classes involves considerable geographical and social change, to which social and cultural institutions will have to adapt. The new classes are bringing about a shift in values, attitudes and preferences. It seems some Western commentators never tire of speculating about how this may give rise to more Western-style liberal democracies, but there is little evidence to support this idea. In fact, what have often been seen as 'middle-class' interventions in politics in Asian countries have not necessarily led to greater democracy in the past. Asia's consuming classes are diverse and fragmented, and they are generally more comfortable with state authoritarianism than were the bourgeoisie and middle classes when liberal democracy was forged in the West. Still, the consuming classes in Asia will take action to protect their property rights, the value of their credentials and the rule of law. In this way they can be expected to challenge elites and have a somewhat transformative effect on governance.

Meanwhile, the environmental issues raised by the growth of the consuming classes are perhaps the most urgent and interesting of all. The metabolism of a city produces vast amounts of waste, much of it the result of household consumption. It has often been noted that as countries industrialise local pollution levels tend to follow a Kuznets curve: in the early stages of industrialisation pollution increases rapidly, but once a country reaches a certain level of prosperity citizens demand a cleaner environment and the country's new wealth allows it to put some environmental quality controls in place, so pollution levels begin to come down again. Although pollution in Asian countries receives a lot of media attention, a 2007 UN Environmental Programme report suggests the rate 
of pollution in many of them is lower than it was in Western countries at similar levels of industrialisation. And a recent econometric study of Asian economies by the Asian Development Bank shows that after controlling for the level of development, higher levels of urbanisation are actually associated with lower levels of pollution.

\section{$\mathbf{G}$} REENHOUSE gas emissions stand apart as something that consumer choices can exacerbate or help ameliorate. Climate change is a genuinely global environmental problem and mitigation is a classic prisoner's dilemma-every country stands to gain by encouraging other countries to contribute the most to mitigation while doing as little as possible themselves. After an exhaustive study of the policy options for dealing with this dilemma from an economic perspective-that is, using the usual 'sticks' and 'carrots' of market forces and government regulation-Nicholas Stern concluded that while conventional policy instruments are absolutely essential for solving the problem, they are not sufficient. An added element is required, namely public policy aimed at changing attitudes and preferences.

In his famous 2006 Review for the UK government Stern wrote: 'Refusing to move the argument beyond one of "sticks" and "carrots" would miss much of what is important to policy formation on climate change. Alongside the influence of preferences in the community, leadership by governments, businesses and individuals is important in demonstrating how change is possible.'

Stern's report showed that lifestyles-including those aspired to, as well as those actually livedneed to change around the world.

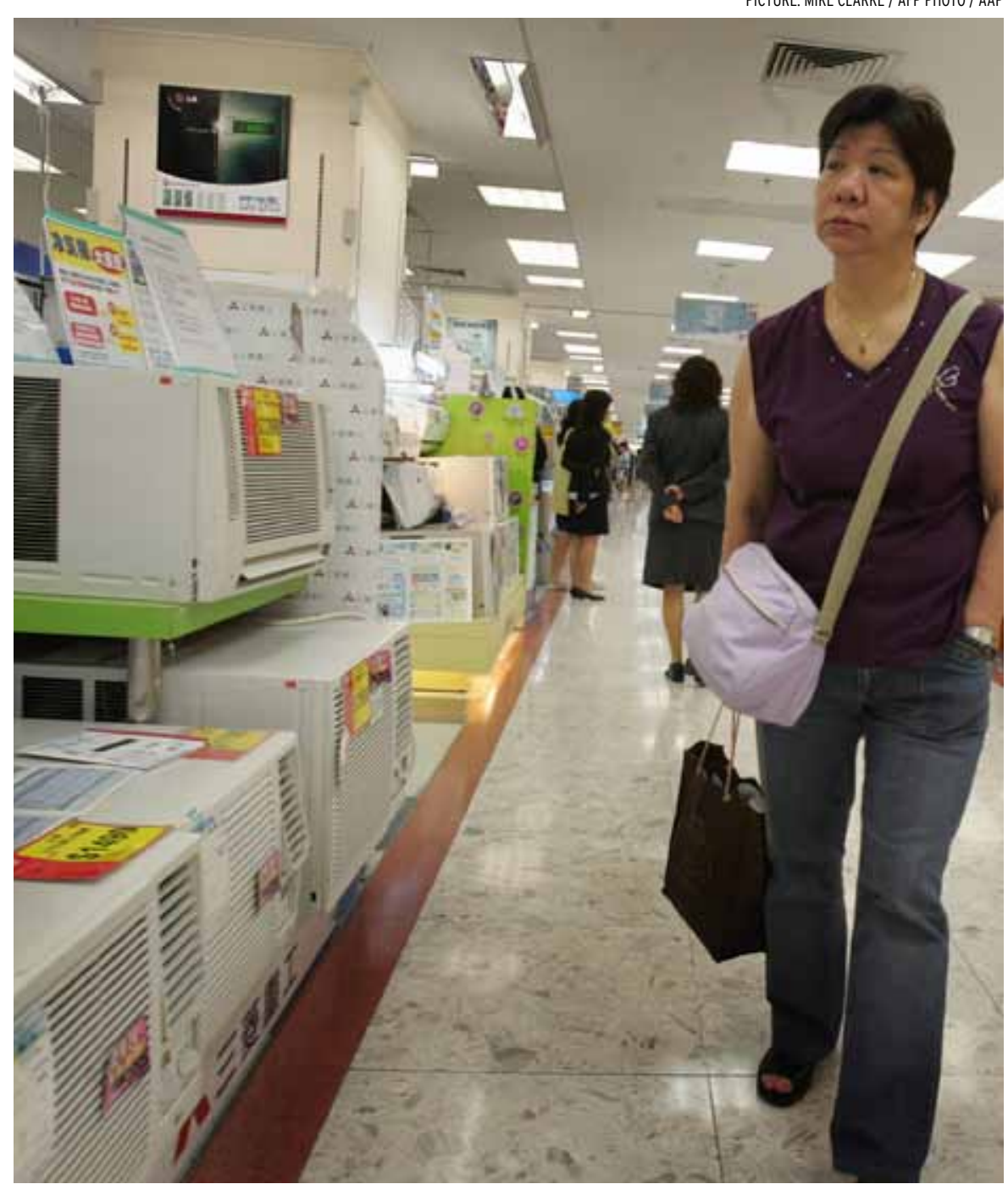

A shopper peruses the choice in air conditioners in Hong Kong, where at the height of summer air conditioning can account for up to 60 per cent of electricity consumption. The size and influence of Asia's consuming classes could make them an important part of a global solution to climate change.

One way to bring about that change is to educate people in responsible consumer behaviour and to encourage environmentally friendly consumption patterns. The sheer size and growth of Asia's consuming classes combined with their potential to transform the societies they live in means they could be an important part of any global solution. The fact that many new consumers are only just figuring out what to do with their growing wealth provides an opportunity. Policymakers and researchers need to pay attention to how lifestyles are evolving in Asia and how they can be made more sustainable. How the consuming classes of the region spend their money is a question of global significance. EAFQ
Adrian C. Hayes is the inaugural chair of the International Union for the Scientific Study of Population's Scientific Panel on Climate Change and Adjunct Associate Professor of Population at the Australian National University. 


\section{New families arise from nature's disasters}

HELEN JAMES

A SIA, which hosts the largest proportion of the world's population, suffers the most from the world's natural disasters. Between 1999 and 2008, Asia was affected by 40 per cent of the world's identified natural disasters. Of the 2.7 billion people worldwide who were affected on average on each of those years, 85 per cent were Asian. Asian countries also incurred 64 per cent of the estimated total US $\$ 4.4$ billion costs.

In view of these losses, on the 10th anniversary of the Great HanshinAwaji Earthquake in Kobe, the UN International Strategy for Disaster Reduction developed the Hyogo Framework for Action 2005-2015: Building the Resilience of Nations and Communities to Disasters. It set out a policy agenda encouraging countries to mitigate risks, enhance preparedness and reduce vulnerability to disasters. The public policy focus subsequently shifted from postdisaster response and recovery to community and individual resilience, identified by Norris et al (2008: 127, 135) as a 'process linking a set of networked adaptive capacities to a positive trajectory of functioning and adaptation in constituent populations after a disturbance'.[emphasis added].

In recent years, the resilience of Asian populations affected by major natural disasters has been apparent in the varied approaches to forming new families. For example, in China in the wake of the devastating earthquake in Sichuan province in May 2008, exceptions to the country's one-child policy were introduced for those who had lost children or spouses. The death toll ranged from 80,000 (the official figure) to over 400,000 (according to a Taiwan researcher) across 11 provinces.

Initial research suggested that within two years of a disaster, there were perceived trends to seek to replace lost children, to find a new spouse and to rebuild, as part of the psycho-social aspects of recovery.

At Yingxue, the epicentre of the 2008 earthquake, an attractive newly built town commemorates the many town children who were lost when the primary and middle schools collapsed. A memorial conference park is situated opposite the former schools site.

At Beichuan, another town in the disaster zone, 20,000 of the town's 30,000 people died. The entire town has been preserved as a memorial site while, at a cost of more than

It was recognised that the physical reconstruction of buildings would not be sufficient to set the community on its pathway

to recovery
US $\$ 2$ billion, a new city has been built some 50 kilometres away, in an ostensibly safer area. This cost was borne by the prosperous province of Shandong at the direction of the central government. Again, the site of the collapsed schools is preserved as a memorial at which haunting music continually plays while a steady stream of mourners attends. Here, the local UN Population Fund chief and mayor of the town provides evidence that about 1400 women have so far had approval to have a 'replacement' child. However, given that many of the children were teenagers at the time of the disaster, and their mothers would have been past the normal childbearing age, the central government and the provincial governments have felt it imperative to provide special reproductive services to assist these women, where applicable, to have another child.

In this case, the central government considered that the extensive losses caused by the disaster and its impact on the next generation presented a potential spark for civil unrest. Public policy thus centred on addressing both the emotional and physical concerns of the survivors. It was recognised that physical reconstruction of buildings would not be sufficient to set the community on its pathway to recovery.

A similar earthquake in 2003, south-west of Bam, Iran, provides a contrasting case. The earthquake levelled the town and the ancient citadel and caused over 30,000 deaths. As part of the recovery effort, 


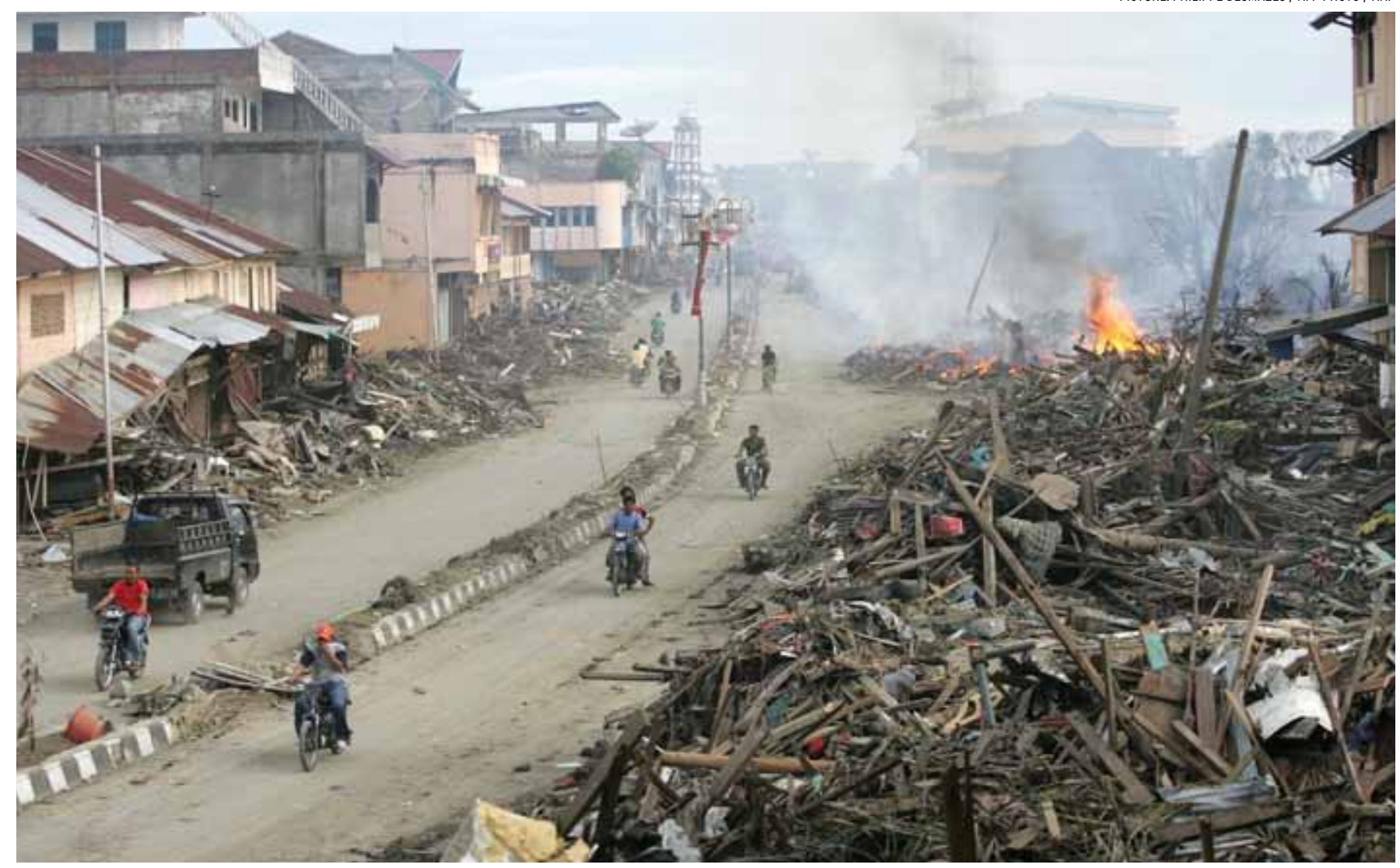

The devasted streets of Meulaboh, Aceh, after the earthquake and tsunami in 2004. Despite the personal and social loss caused by such natural disasters, evidence points to the resilience of Asian populations in rebuilding family life.

government policy has been to provide financial assistance and incentives for families to re-form, in accordance with cultural and religious values. Evidence to date suggests that where the surviving partners originated from Bam, the new families formed appear to have thrived; but where one of the new partners (perhaps lured by government incentives to land ownership in the area) comes from a different part of Iran, the subsequent marriages frequently failed. In Bam, the human inclination to replace lost children and lost families is again apparent.

In Myanmar, this pattern is repeated in the Irrawaddy delta, which was devastated by Cyclone Nargis in May 2008, with over 140,000 dead or missing. There were no deaths in the delta's south-west, among the Karen villages near the town of Amar, but all the dwellings were destroyed when a two-metre-high wave swept through the area. Villagers and local nongovernment organisations helped in reconstruction. In one village of 1400 people, 133 children have been born since 2008, or around 30-40 per year since the cyclone. The Burmese village of Byi Chaung on the south-eastern side of the delta had a pre-Nargis population of around 300. It lost one third of its population in the storm, 70 of whom were children. Here a similar post-disaster birth rate appears to have occurred. The village population in November 2012 stood at around 500. Some 23 marriages occurred since Cyclone Nargis, producing around 20 children per year since 2009.
While the above data are preliminary, the pattern of seeking to re-establish a family circle after losses, and of seeking to bring 'replacement' children into the world, appears to be occurring in all three of these widely disparate cultural and governance contexts. The pattern also seems to be correlated with psycho-social recovery and is independent of the physical reconstruction context which, again, in all three cases, is widely divergent. This suggests that the long-term demographic impact of major disasters in Asia requires further extensive research. EAFQ

Helen James is Associate Professor at the Australian Demographic \& Social Research Institute, the Australian National University. 


\section{PETER MCDONALD}

N THE immediate post-war years, two prominent American demographers were attached to the MacArthur administration in Japan. One was Warren Thompson who, from the 1920s, had been an advocate of control over population growth as a necessary condition of economic development in developing countries. The other was Frank Lorimer, who was associated with the Princeton group of demographers which, from the late 1940s, began to argue that family planning was a necessary precursor to development in third world countries. Before this, according to demographic transition theory, control over fertility had been seen as a consequence of development. Fertility in Japan fell rapidly from around 3.7 births per woman in 1950 to around the replacement level of two births per woman in 1960 and development took off much as had been predicted.

This was also the beginning of the end of the colonial era and, one by one, developing countries were gaining independence. In the Cold War context, there was a battle for the hearts and minds of the developing countries. A series of books produced by American demographers in the 1940s and 1950s, culminating in Coale and Hoover's 1958 book Population Growth and Economic Development in Low-Income Countries, argued the case for control of population growth through concerted family planning programs. Lower birth rates would concentrate the population in the workforce age group and allow scarce capital to be spent on investment rather than consumption. A lower birth rate also meant smaller families, which allowed both parents and the state to put a greater proportion of income towards children's education. One by one, developing countries in Asia adopted this approach. Early participants were the Asian tigers: South Korea, Taiwan, Singapore and Hong Kong, and in these countries economic development took off. Ironically, this capitalist idea was adopted in the communist countries, China and Vietnam, from the 1980s onwards.

The theory was that dissemination

Some argue that the

effects of very low

fertility can be offset

by further increases in

education, meaning the

nation is smaller but

smarter. Migration may

also be a partial solution of control over fertility would lead to the result observed in Japan in the 1950 s and 1960s, that fertility would fall to the replacement level of two children per woman and then remain at that level. Even China's one-child policy was designed to reduce fertility to about replacement level. However, in every Asian country where fertility has fallen to replacement level, it has continued to fall often to levels described as very low fertility, that is, under 1.5 births per woman. In Asia, very low fertility is found in Japan, South Korea, Taiwan, Hong Kong, Macau, Singapore, Thailand and probably China.

It is widely considered that very low fertility results from the barriers faced by women, now better-educated and more career-oriented, to combine work with family responsibilities. This is particularly an issue in advanced East Asian economies because of the long hours of work that are expected from full-time workers and the difficulty of finding part-time work that is not low-level work. Employers are unwilling to change the current working conditions because they fear they will lose whatever competitive advantage they may have.

In the short term, very low fertility increases GDP per capita because both households and nations benefit from the reduced costs of having fewer children. In the longer term, however, the size of the labour force falls sharply, the total population size spirals downward and the population ages dramatically. These longer-term 


\section{MAKING A MATCH}

effects are already well under way in Japan. Socially, in the short term, the legitimate desires of young couples to have children are frustrated. For example, the desired family size of couples in Japan has never fallen below two. And in the longer term, society may adjust itself to the absence of children, making reversal highly problematic (the low fertility trap hypothesis). An absence of children and young workers may also generate a 'demographic malaise'-a deficit of incentive-as has been claimed in the Japan case.

What is to be done? Some argue that the effects of very low fertility can be offset by further increases in education-meaning the nation is smaller but smarter. Migration may also be a partial solution. Singapore, somewhat reluctantly, has followed this course. The inexorable mathematics of very low fertility mean that this is not a total solutionfertility must increase in the future. Aware of this, all governments in Asia with very low fertility-with the exception of China, for the time being-have expressed their desire to increase the level of fertility to a sustainable level. And most have already tried to do so with little success. Inappropriately, given their low tax regimes, they have looked to the Nordic countries and France for solutions. They need to be looking instead at the approaches that have kept fertility at relatively high levels in English-speaking countries, especially family-friendly working conditions.

Peter McDonald is Professor of Demography and Director of the Australian Demographic and Social Research Institute at the Australian National University.

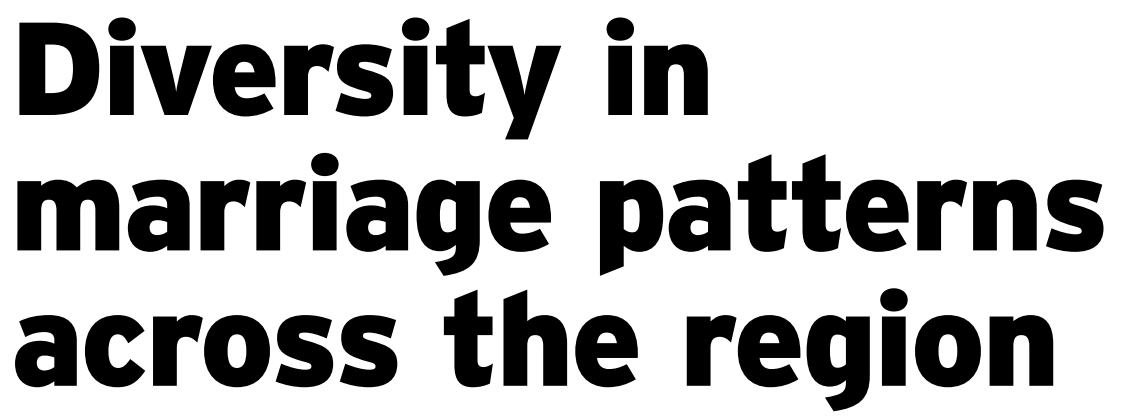

GAVIN W. JONES

A

\section{S COUNTRIES in Asia go} through difficult demographic transitions, marriage patterns have never been more important. Asia was traditionally characterised by universal marriage-defined as when fewer than 5 per cent of women have not married by the age of 50 . But this is no longer the case: over recent decades countries in East and Southeast Asia have seen the demise of universal marriage, and this has directly contributed to declines in fertility in many countries to ultra-low levels because there is almost no childbearing outside marriage. Yet in other parts of Asia, especially in South Asia, it is not the failure of people to marry that is of concern but the persistence of high levels of teenage marriage, much of it occurring below the legal minimum age. This is the case, for example, in Nepal, Bangladesh and India.

Marriage patterns across Asia are diverse. Though many countries in East and Southeast Asia now show patterns of very delayed marriage, not all of them do. The people of Japan, South Korea, Taiwan, Thailand and Myanmar marry late, while the people of Indonesia marry earlier. Almost all women in China are married by the time they reach age 30-but this pattern is not repeated by ethnic Chinese populations elsewhere in the region (including Hong Kong), which have extreme patterns of delayed marriage. Interestingly, it is not that women marry very young in China, but rather that marriages are concentrated in the 20s to a much greater extent than in other East and Southeast Asian countries.

What has been responsible for these remarkable differences in marriage patterns? In many East and Southeast Asian countries, delayed marriage can be linked to rapid economic development, rapidly advancing educational levels for women and related changes in employment patterns. Traditional arranged marriage systems have collapsed, and women, who no longer need a husband for financial security, are delaying marriage. Given the changing balance in the pool of potential spouses, with a much higher ratio of well-educated women to well-educated men than before, traditional attitudes are getting in the way. Women in the region still prefer to marry up, and men are often reluctant to marry someone who is better educated or makes more money than they do. To add to these factors, effective matchmaking procedures have not emerged to replace the earlier arranged marriage systems. It all makes for a large population of singles who would actually like to marry. On the other hand, there are people who deliberately choose not to marry, often because of a desire (particularly on the part of women) to avoid what goes 
along with marriage-having children, the stresses of managing a career and childraising, and caring for parentsin-law as they age. Uncertainty in the labour market and the high financial costs of raising children are also relevant issues. The exact ratio of singles by choice and singles by circumstance is unclear.

By contrast, in South Asia arranged marriage systems have shown great resilience. Why has this been the case in the patriarchal and patrilocal family systems of South Asia but not the patriarchal and patrilocal Confucianist-influenced family systems of East Asia? (Southeast Asia is in a category of its own because it has bilateral kinship systems, meaning more flexibility in such things as inheritance and post-marriage residence). Part of the explanation may be simply a 'developmental' one: East Asian countries have experienced sustained and rapid economic growth, and rapidly rising levels of female education. In South Asia, these developments have been much slower. Whatever the reason, high levels of parent-arranged teenage marriage are still the case in north India, Bangladesh and Nepal, although Pakistanis, on average, get married considerably later. Many of these arranged marriages take place below the official minimum age for marriage and in contravention of

\section{EASTASIAFORUM Quarterly}

IN OUR NEXT ISSUE ...

\section{The Asian Century}

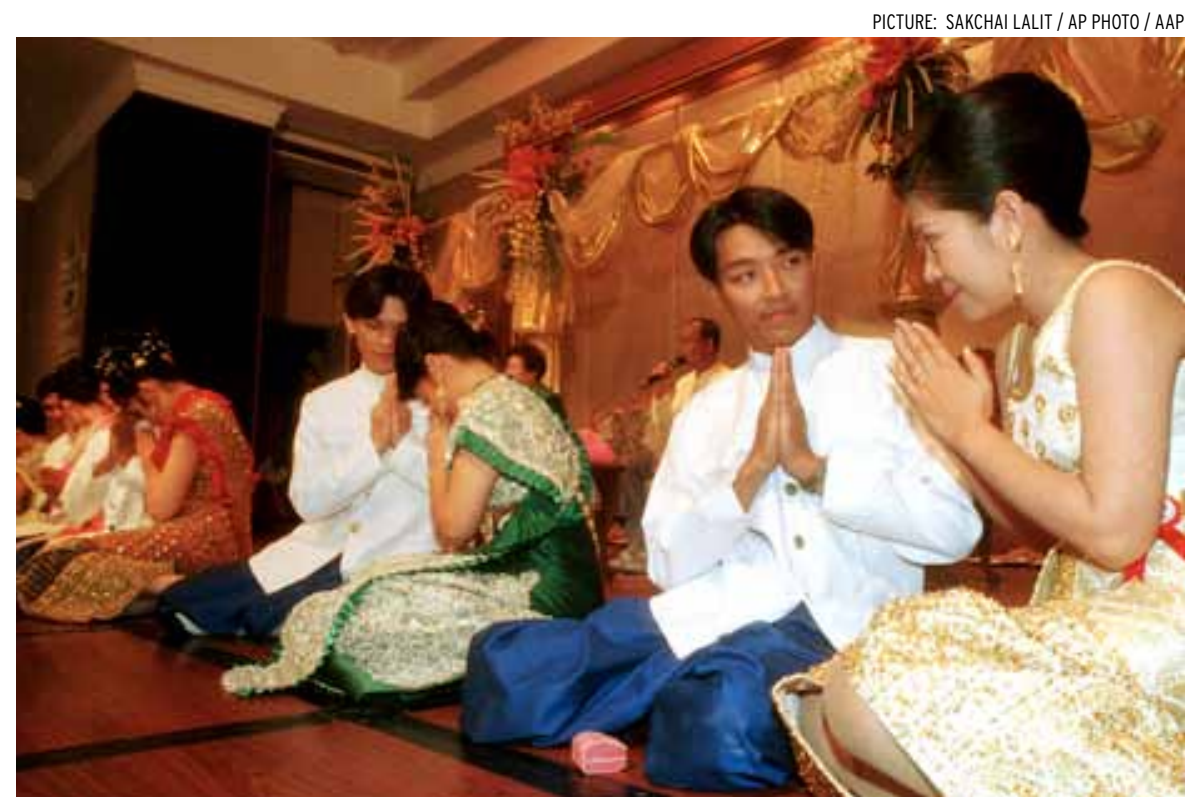

Thai couples at a Valentine's Day group wedding ceremony in Bangkok. Thais are among those Asian peoples who tend to marry later. In many places traditional arranged marriage systems have collapsed.

Article 16 of the Universal Declaration of Human Rights, which states that 'marriage shall be entered into only with the free and full consent of the intending spouses. The young brides also tend to give birth at a very early age, which leads to adverse health consequences for both mother and child. Marrying at a very young age also normally makes it impossible for girls to complete their education and perpetuates the unequal power relationship between women and their typically much older husbands.

\section{$\mathbf{T}$} HE RISE in singlehood in East Asian countries shows no signs of levelling off; indeed, if anything, it has accelerated in Japan and South Korea over the past decade. Governments are nonplussed about possible policy levers to encourage marriage. Singapore has gone much further than other countries in trying policy approaches, including direct government involvement in matchmaking, but has had little obvious success.

Asian countries are just as diverse in patterns of breakdown of marriage as of entry into marriage. While the high divorce rates in Malay-Muslim populations fell drastically in the 1960 s and 1970s, divorce rates throughout East and Southeast Asia appear to have been generally on the rise since the 1980s, partly because the stigma attached to divorce appears to have faded. But divorce rates remain generally very low in South Asian countries. Rather than reflecting more harmonious marriages, low divorce in this region is because the marriage system does not permit the 'escape route' of divorce.

Overall, then, trends in forming and dissolving marriages in Asian countries are the outcome of the interaction of socio-economic development and cultural systems. Not surprisingly, the outcomes across the region are diverse. EAFQ

Gavin W. Jones is Professor of Sociology and Director of the J. Y. Pillay Comparative Asia Research Centre at the Global Asia Institute, National University of Singapore. 


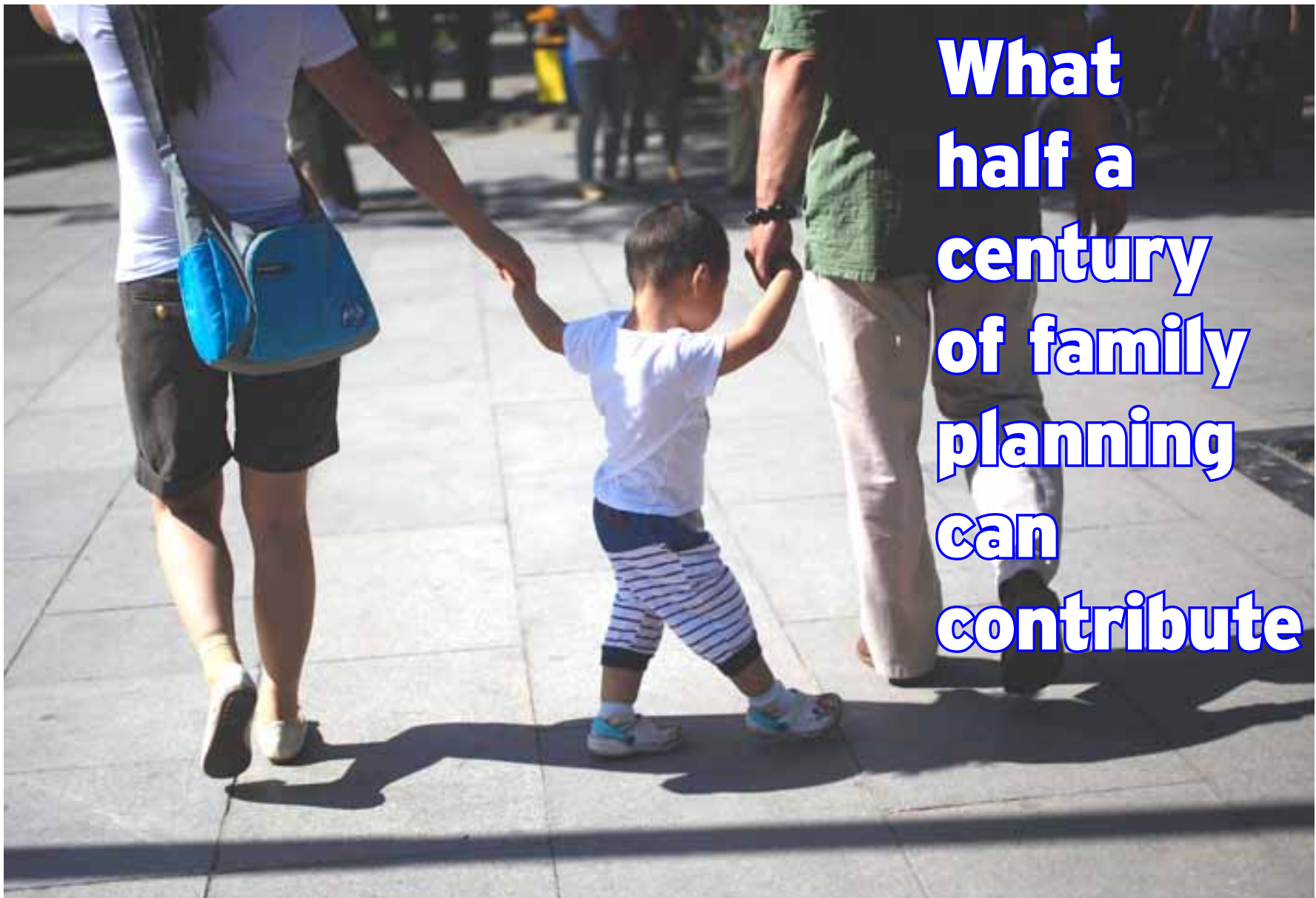

\section{AMY TSUI}

S OME five to six decades ago, between 1951 and 1965, a rather remarkable chain of events took place in Asia, the Pacific and the Middle East: countries began to use family planning programs to address rapid population growth, and many subsequently experienced extraordinary economic growth.

India, Pakistan (then including Bangladesh), the Republic of Korea, China, Fiji, Egypt, Singapore, Sri Lanka (then Ceylon) and Turkey all implemented family planning programs. By 1976, the governments of Indonesia, the Philippines, Thailand, Vietnam and Nepal had also declared their population growth and fertility rates too high and provided direct support for contraceptive access. Government after government declared support for national family planning programs, and formed inter-ministerial coordinating boards, councils and commissions to address population concerns and organised the top-to-bottom provision of family planning services. The supervising boards or commissions were frequently administered under prime ministers' offices.

Family planning efforts were linked to fertility reduction and in turn to slowing population growthpolicy goals that aimed to enhance a country's prospects for economic development. As well as attempting to control fertility, governments sought to lower child mortality, eradicate infectious diseases, increase education levels, improve nutritional status and food security, modernise agriculture and expand their economies with manufacturing and industrialisation.

Not many now see family planning as a central element to national economic development. Rapid population growth is no longer considered a global or local risk, fertility reduction is not politically correct, and family planning has been absorbed into a larger pantheon of reproductive health needs for human, rather than economic, development. The Millennium Development Goalsfirst adopted in 1990-only addressed family planning when universal access to reproductive health was adopted as a target for maternal health in 2005. But for Asia, the development perspectives that prevailed in the 
1960s and 1970s saw family planning and fertility decline as necessary steps to facilitate economic growth.

At that time, the region saw robust and in some places quite rapid fertility declines-particularly in China, South Korea and Thailand-and, as a consequence, changed population age structures. With fewer births, higher ratios of persons of working age (those aged 15-59) to those of dependency age (those aged $0-14$ and 60-plus) emerged. Take South Korea as a typical example. There the proportion of the population under 15 was 42 per cent in 1970. It dropped by half to 21 per cent in 2000, while the proportion of working age people (15-59 years) rose from to 52 to 68 per cent in the same period. The ratio of workers to youth went from 1.24:1 to $3.24: 1$. The total fertility rate dropped from 4.5 to 2.4 in this time and the proportion of childbearing-aged married women practising contraception rose from 24.5 per cent to 79.3 per cent.

This scenario was replicated in many countries, and as a result the region began to experience the 'demographic dividend'. This term, coined in 2003 by David Bloom and David Canning, refers to the economic growth that results from changes in population age structure as a result of a fertility decline. Lower fertility rates produce smaller youth cohorts, and the government is then able to spend relatively less on basic health care, education, food and housing for the young, and invest relatively more in business, infrastructure, job skills training and the economy.

Estimates by economist and demographer Andrew Mason, codirector of the National Transfer Accounts project, suggest that in the mid-2000s the demographic dividend in East and Southeast Asia contributed as much as 1.9 per cent of an annual growth of 4.32 per cent in GDP per consumer (weighted for age-related consumption). For South Asia, he estimated that the dividend contributed 0.79 per cent of 1.88 per cent of actual economic growth. The economic growth resulting from balanced age structures has been substantial. Moreover, the demographic dividend's economic benefits have been enduring. While it is popular to despair of countries' ageing populations, Dr. Mason and his NTA colleagues show that with proper financial mechanisms encouraging worker savings and investments in property, businesses, pension funds or other assets, the demographic dividend can continue to pay out as Asia ages. If private, especially family, transfers to the elderly can be built up, people will rely less and less on government support.

Today, partly thanks to the demographic dividend, 49 per cent of women in Asia are in the labour force, compared with 80 per cent of men. In 2010 the per capita GNI (by purchasing-power-parity) in East and Southeast Asia ranged from US $\$ 3070$ in Vietnam to US\$31,110 in South Korea, and to US\$58,700 in Singapore. The average human development

Today, partly thanks to

the demographic

dividend, 49 per cent of

women in Asia are in the labour force, compared with 80 per cent of men. index value is a strong 671 out of 1000 for the region. The average number of children expected per childbearingaged woman is near or just below 2.0 and three-quarters of couples use contraception.

In the late 1960s, when India established its Ministry of Health and Family Planning, or in 1970 ,when Indonesia established its National Family Planning Coordinating Board, it was impossible to foresee a day when contraceptive use would become routine health behaviour, much like vaccinating children. Today, while some couples may obtain their contraceptive care from government clinics, most seek private sources and pay for these services through health insurance or out of pocket. Such a situation of contraceptive security, enjoyed at the individual couple level, is one that remains out of the reach of some 222 million women and their partners in low-resource settings in sub-Saharan Africa and parts of South Asia. The 2012 London Summit on Family, co-sponsored by the Bill \& Melinda Gates Foundation and the UK Department for International Development, declared a goal of ensuring 120 million women and their partners, in 69 low-income countries, have access to contraception by 2020. The lessons of Asia's economic development plans and benefits of the demographic dividend in the region may be a source of inspiration for these countries. As the UN begins to frame global development goals for beyond 2015 they would do well to consider demography and family planning.

Amy Tsui is Professor at the Bloomberg School of Public Health, Johns Hopkins University, and Director of the Bill E Melinda Gates Institute of Population and Reproductive Health. 


\section{Contraception, a family planning imperative}

\section{BAOCHANG GU AND YAN CHE}

$\mathbf{R}$ EGULATING childbearing through contraception, particularly via modern contraceptives, revolutionised human reproduction in the 20th century. It is also crucial to achieving United Nations Millennium Development Goal 5 (MDG 5) - that is, to provide universal access to reproductive health and reduce the maternal mortality ratio by three-quarters. Between the ages of 20 and 44, a fertile, sexually active woman is capable of giving birth about 12 times, even if she breastfeeds each baby for one year. Thus, to limit her family to $2-4$ children, for example, a sexually active woman would have to effectively practise contraception for 16-20 years of her roughly 25 childbearing years to avoid unplanned pregnancies and a need for abortion.

A variety of contraceptive options are now available worldwide. Couples can use traditional methods, such as periodic abstinence and coitus interruptus. Alternatively, they can adopt modern contraception, including the oral pill, condoms, injectable contraceptives, implants, intrauterine devices (IUDs) and male or female sterilisation. Modern contraceptive methods are much more effective

Relationship between the prevalence of contraceptive use and unmet need for contraception and total fertility rate in Asia

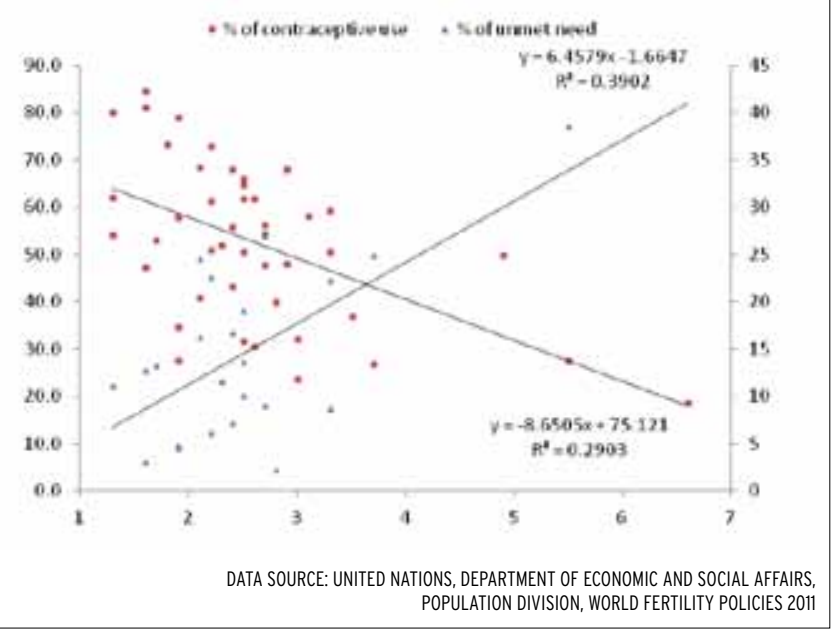

than traditional methods. For instance, the failure rate of sterilisation is less than 1 per cent, compared to 25 per cent for periodic abstinence.

Asia is home to 66 per cent of the world's 1.2 billion married women who are aged 15-49. Two-thirds of them use some form of contraception, compared with 48 per cent in 1980. Thus the prevalence of contraception in Asia has increased by about 40 per cent during the past 30 years.

Yet the prevalence of contraceptive use varies greatly by region across Asia. It is relatively higher-about 83 per cent-in East Asia, and a bit lower-54-57 per centin South, West and Central Asia. The use of modern contraceptive methods also varies, ranging from 81 per cent in East Asia to 36 per cent in West Asia. Variation between countries is even greater, ranging from 19 per cent in Afghanistan (with modern methods accounting for 16 percent) to 85 per cent in China (with modern methods accounting for 84 per cent).

Regional differences in method-use patterns also vary substantially across Asia. Overall, the most commonly used contraceptive method in Asia is female sterilisation, which accounts for 32 per cent and 52 per cent of married contraceptive users in East and South Asia, respectively. However, this result is mainly attributable to the large numbers of sterilisations in India and China. The compulsory sterilisation of a couple after they had had a certain number of children was applied to all Indian citizens residing within the country until the mid-1990s. And in many Chinese provinces, it was common practice for women to be asked to adopt an IUD after their first birth and to undergo sterilisation after the second. This was the case until 'informed choice' was introduced to the family planning program in the mid-1990s. Currently, the prevalence of female sterilisation is 37 per cent in India and 28 per cent in China.

With 140 million users, who account for 18 per cent of married women of reproductive age, IUDs are the second most popular contraceptive method in Asia. In Central Asia, 26 per cent to 50 per cent of married women aged 15-49 use IUDs, accounting for 63 per cent to 77 per cent of the region's married contraceptive users. The IUD is also 
very popular in East Asian countries like North Korea, China and Mongolia, with use ranging from 44 per cent to 62 per cent of married, contraceptiveusing couples.

Much of the IUD's popularity stems from its effectiveness and long-lasting nature. Its failure rate is less than 1 per cent over the first year and about 2 per cent over 10 years of use. Its use involves only one action and is reversible. The IUD is thus highly appreciated in developing countries, particularly in rural areas.

However, this method is much less popular in South Asia. For example, in India only about 2 per cent of women using contraception rely on IUDs. The low rate of use is largely attributable to the inadequate training of personnel and lack of facilities to handle side-effects, as well as the absence of efficient follow-up services. This situation partially reflects the Indian Government's preference for irreversible contraceptive methods as a way to control the country's rapid population growth. Since IUD insertion and removal both require medical involvement, difficulty in accessing medical services may also be one of the main reasons for low usage in poor Asian countries like Afghanistan.

C ONDOM use has increased globally in recent decades. One important reason is the effectiveness of condoms in preventing HIV/ AIDS and other sexually transmitted infections (STIs). When used consistently and correctly, condoms prevent 80-95 per cent of potential HIV transmissions. Yet the effectiveness of condoms depends on the user. For typical users, the failure rate is about 15 per cent over the first year of use; for those who use it correctly, however, the failure rate

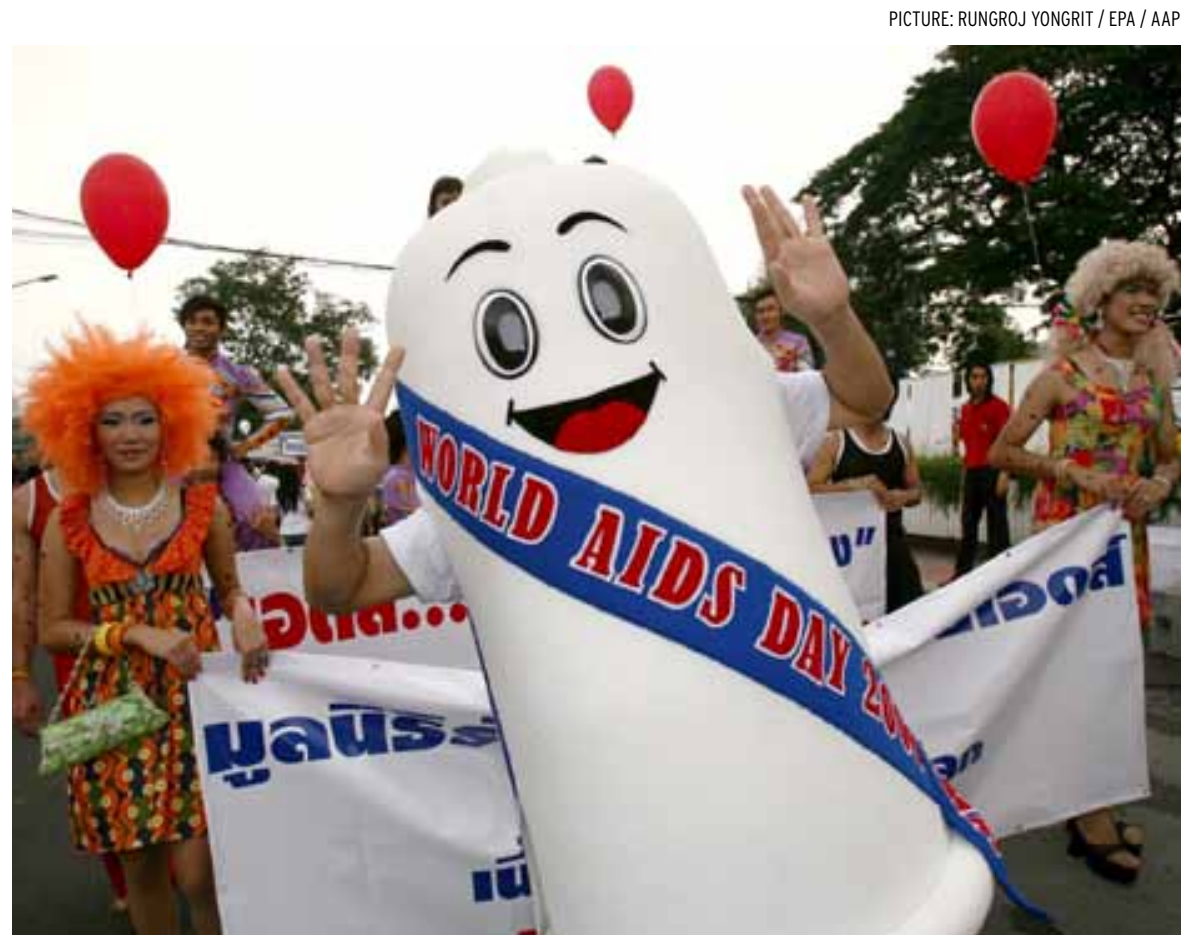

Condoms on parade in Bangkok. The devices are effective in preventing the spread of AIDS but are only the third most popular contraceptive method in Asia.

reduces to about 2 per cent.

Condoms are the third most popular contraceptive method in Asia, but are only used by 54 million Asian couples, or 10 per cent of contraceptive users. The low prevalence of condom use in many Asian countries may result in part from a cultural bias against male methods of contraception. However, it is particularly favoured in three more-developed Asian countriesJapan, South Korea and Singaporewhere condom use ranges from 22 per cent to 41 per cent of those using contraception. The total fertility rate of these three countries is around 1.3, the lowest across Asia, which could partially stem from the popularity of condoms in these countries. In Japan, the government has issued condoms to prevent STIs since World War II, while oral pills and IUDs were not officially approved until 1999. Condoms were thus the only available modern contraceptive method in Japan for a long time.

Hormonal contraceptives, including the oral pill, injectables and implants, are used by 10 per cent of married contraceptive users in Asia. The oral pill alone accounts for 6 per cent. Pill use varies across the region, ranging from about 1 per cent in East Asia to 16 per cent in Southeast Asia. Although the oral pill is one of the safest contraceptive drugs, ill-informed concerns about its side-effects and the inconvenience of having to take it regularly may have prevented more widespread acceptance in Asia.

Traditional methods are practised by 6 per cent of married women aged 15-49 in Asia. They are most popular in West Asia: between 10 and 30 per cent of married women of reproductive age in most West Asian countries practise traditional methods, which may partly be due to religious reasons. However, the popularity of traditional methods in Japan (17 per 
cent) may largely be due to the limited choice of modern methods other than condoms.

Many factors influence prevalence and patterns of contraceptive use, such as a method's availability and women's characteristics and preferences. In turn that reflects differences in geographic and cultural contexts and the development of family planning policies across Asia. While much of the increase in contraceptive use reflects a transition from high to low desired family size, it also reflects the continuing efforts of national and international family planning organisations and a wider availability of contraceptive choices.

The graph on Page 28 shows two regression lines. One presents the relationship between contraceptive prevalence and total fertility rates among 45 Asian countries. The leastsquares regression line shows the expected inverse relationship between contraceptive use and fertility at country level. The other line shows that the level of unmet need for contraception increases along with the total fertility rate, suggesting the desire for smaller families seems to be outpacing the availability and use of contraception in Asia, which may lead to unwanted births and high rates of abortion in some countries. Strengthening family planning services should therefore be given a high priority in countries with a high level of unmet need. EAFQ

\section{Baochang Gu is Professor of Demography at the Center for Population and Development Studies, Renmin University of China.}

Yan Che is Professor of Reproductive Health E Senior Epidemiologist at the Shanghai Institute of Planned Parenthood Research.

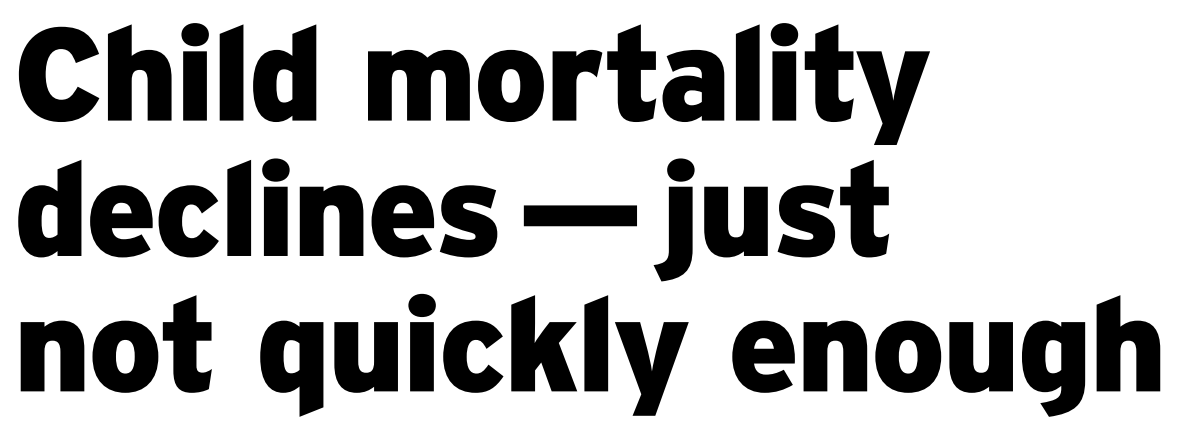

\section{VINH DUC NGUYEN}

$\mathbf{T}$ HE INFANT and child mortality rate has declined remarkably in most countries since 1950. But despite worldwide efforts, the target laid down in the Millennium Development Goals (MDG) - to reduce the underfive mortality rate by two-thirds between 1990 and 2015-appears to be unachievable, not only at the global level but also in Asia.

According to recent $\mathrm{UN}$ estimates, the under-five mortality rate in Asia fell by almost half between 1990 and 2011, from 82 to 42 deaths per 1000 live births. At a regional level, the corresponding reductions were from 48 to 15 in East Asia, 76 to 42 in Central Asia, 116 to 61 in South Asia, 69 to 29 in Southeast Asia and 63 to 30 in West Asia. The average annual rate of decline in under-five mortality in Asia in the period from 1990 to 2011 was 3.2 per cent. The regional rate of decline was highest in East Asia (5.4 per cent), followed by Southeast Asia, West Asia, South Asia, and lowest in Central Asia (2.8 per cent). Although the reductions slightly accelerated in the last decade, this pace of decline is not fast enough for Asia and most Asian sub-regions, except East Asia, to achieve their MDG targets in child survival.

At the national level in 2011, under-five mortality rates ranged widely across countries in Asia, from 2.6 deaths per 1000 live births in Singapore and 3.4 in Japan to 54 in Timor-Leste, 72 in Pakistan and 101 in Afghanistan. Only 23 of 49 countries in Asia are on track to meet the MDG target on child survival. Twelve of them, including Bangladesh, Timor-Leste, China, UAE, Mongolia, Laos, Cyprus, Lebanon, Saudi Arabia, Turkey, Oman and the Maldives already achieved this MDG target by 2011 . On the other hand, among the countries that had an under-five mortality rate of more than 20 deaths per 1000 live births in 1990, Iraq, DPR of Korea, Uzbekistan, Yemen, Pakistan and Myanmar have the lowest rates of decline in under-five mortality (less than 42 per cent) in the period 1990-2011.

It is worth examining the key determinants of child mortality in Asia. First, levels of socioeconomic development can be a proxy for many causes of child mortality. It seems clear that under-five mortality rates, which vary greatly across Asian countries, are strongly associated with levels of gross national income (GNI) per capita, especially in the groups of the mostand least-developed countries.

But UN and World Bank figures show that the pace of child mortality decline and GNI per capita may not be so strongly related. In the period 1990-2011, marked growths in GNI per capita may have significantly contributed to the steep decline in 
under-five mortality rates in Thailand, Singapore, China, Laos, TimorLeste, Turkey, the Maldives, Oman, and Lebanon but were less effective in Indonesia, Sri Lanka and most countries in Central Asia (Tajikistan, Georgia, Kazakhstan, Turkmenistan, and Azerbaijan). Of the countries with relatively low levels of economic growth, the child survival rate has increased only slightly in Myanmar, DPR of Korea and Iraq, but markedly in Mongolia, Bangladesh and Nepal. It suggests that other factors of socio-economic development may be more important than GNI per capita in influencing the decline of child mortality in most Asian countries.

Fertility and child mortality are related, particularly as demography changes, so it is not surprising that a decline in fertility contributes to increased child survival. Previous research confirmed that preceding birth interval, an indicator closely reflecting fertility in many populations,
... it is not surprising

that a decline in fertility

improves the likelihood of

child survival

has considerable impacts on child survival. In nine of the twelve Asian countries that already meet the MDG target on under-five mortality by 2011 , fertility rates have dropped by more than one-third since 1990.

Socio-economic development promotes child survival primarily because living conditions and access to healthcare improve. For instance, according to the UN, immunisation programs in Vietnam and Bangladesh, as well as the promotion of breastfeeding in Cambodia, have significantly contributed to declines of child mortality in these countries.

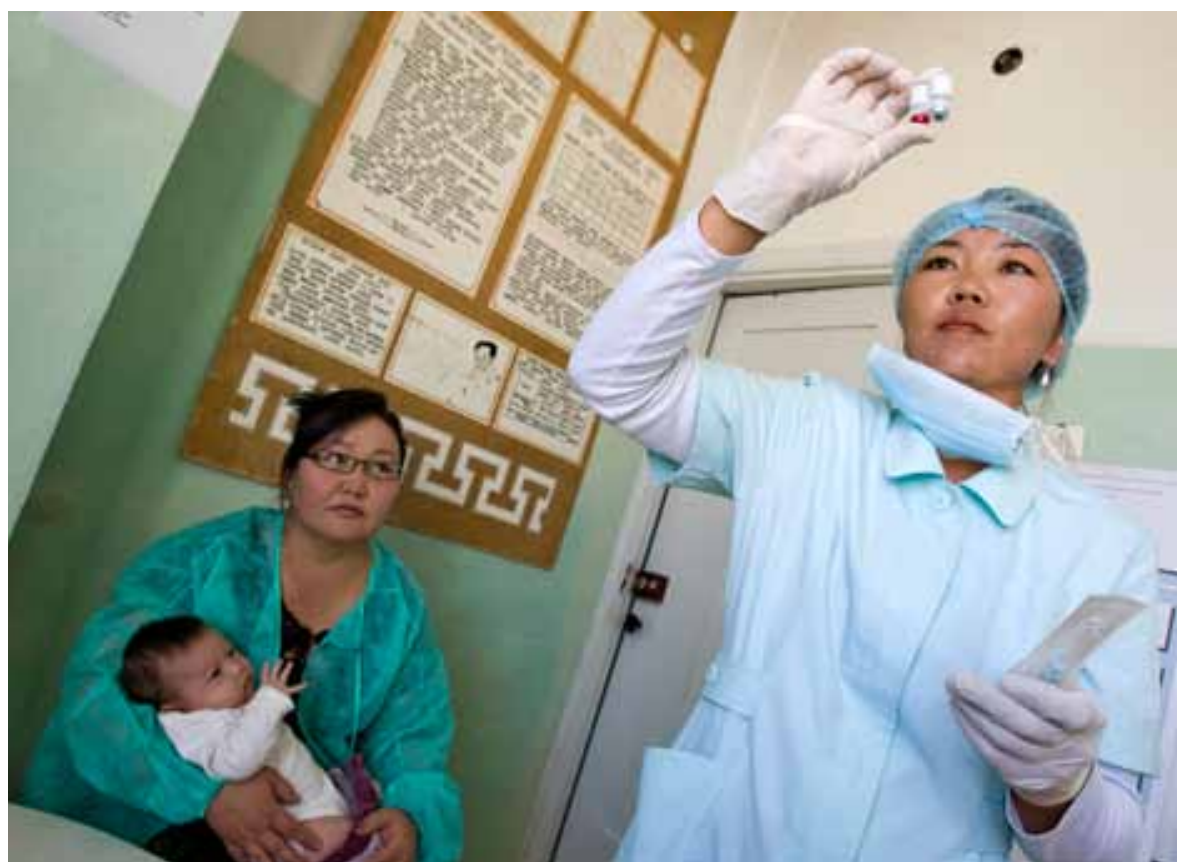

A woman and child at a United Nations-supported family clinic in Khovd Province, Mongolia. Improved access to water and more hygienic conditions have helped to reduce Mongolia's child mortality rate.
The remarkable achievement of Mongolia and Nepal in child survival over the last two decades may not be strongly related to national income or educational attainment, but to their improvement of access to clean water and other hygienic conditions. Meanwhile, the slow decline in the under-five mortality rate in Iraq, Myanmar and some countries in Central Asian in the period 1990-2011 may be put down to their national economic conditions and/or their little improvement in education and healthcare. In developed countries, not only clean water and other hygienic conditions but high quality of healthcare and childcare is necessary for the decrease in under-five mortality rates to less than 10 deaths per 1000 live births.

Isolated successes in parts of Asia suggest that it is possible to reduce infant and child mortality rates quickly even without high rates of economic growth. It is reasonable that a decline in fertility rates would increase rates of child survival, especially in countries with relatively high fertility rates. Further investments on primary healthcare and basic living conditions are still necessary, but once a relatively low rate of infant mortality has been achieved such investments have little effect. The decline in child mortality rates will decelerate when countries have relatively low fertility rates, high vaccination coverage, and easy access to clean water. At that stage, the focus needs to shift to improving the quality of education, healthcare and childcare, even if these improvements seem difficult to achieve without extensive economic development. EAF

Vinh Duc Nguyen is Doctor of Demography at the Institute of Sociology, Vietnam Academy of Social Sciences. 


\section{AIDS: hopes and challenges}

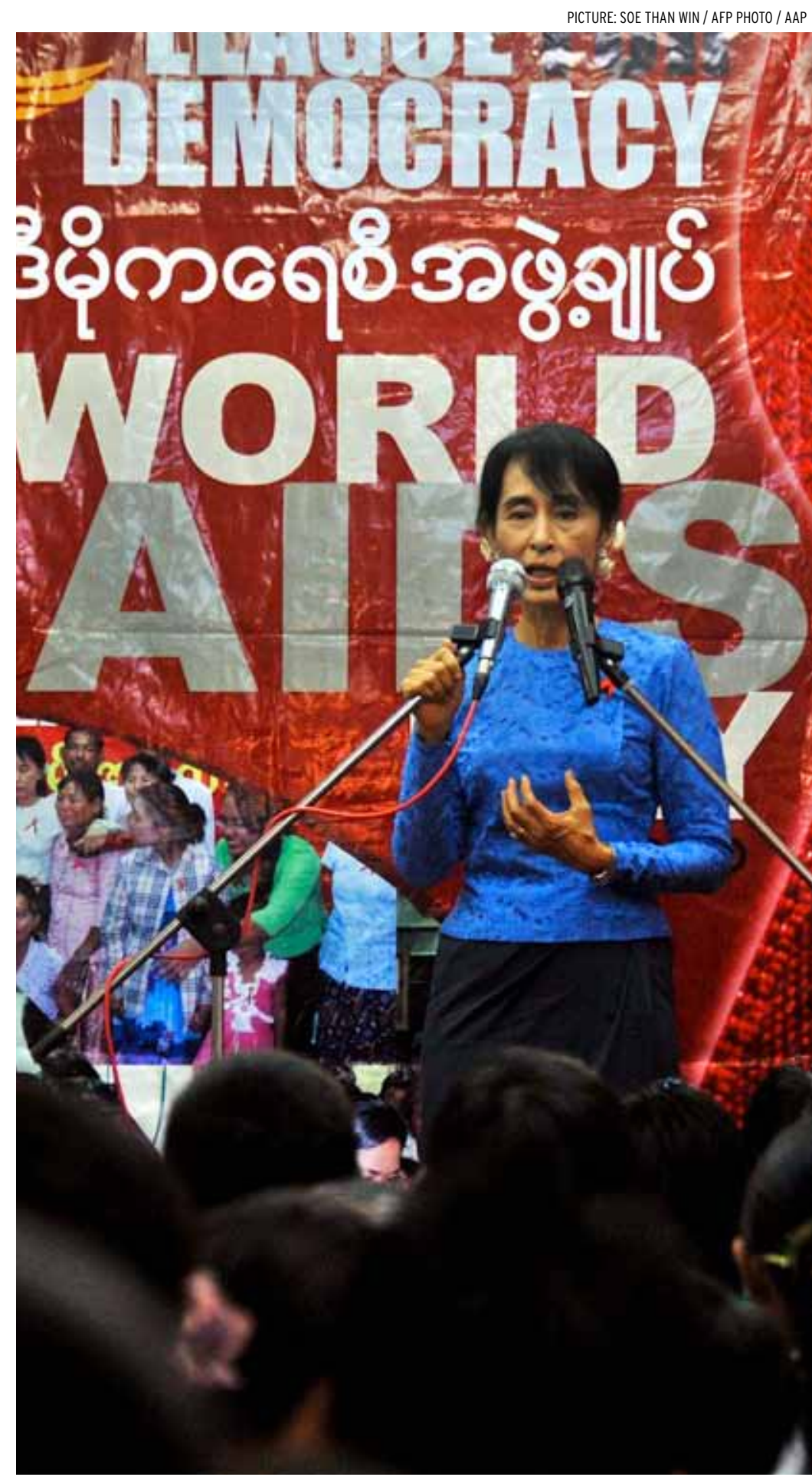

Aung San Suu Kyi speaking to followers at a World Aids Day function at National League for Democracy headquarters. Though Asia has escaped the worst of the epidemic, tackling the condition still requires a comprehensive regional policy response.

\section{BINOD NEPAL}

A IDS has already claimed as many as 30 million human lives worldwide. An estimated 34 million people, mostly adults of working age, are living with HIV, the virus that causes AIDS. Despite this UNAIDS, the peak UN agency that coordinates AIDS control programs worldwide, optimistically affirmed in its 2012 Global Report that the epidemic has come under control in much of the world. Sub-Saharan Africa, the most affected region, has shown remarkable progress in reversing the trend in HIV infections and AIDS deaths. And in Asia, several countries have contained their epidemics well before they grew out of control. The turnaround presents the best hope in the fight against the AIDS epidemic. But is Asia able to maintain the momentum?

The epidemic gripped Asian countries much later than the Americas and sub-Saharan Africa. Until the early 2000s, the course of AIDS in Asia was uncertain. Some commentators believed that it was just a matter of time before the continent succumbed to a catastrophic epidemic. In a continent that accommodates the majority of the global population, including demographic billionaires China and India, even a small rise in the rate of HIV infections would result in millions of additional HIV carriers.

Fortunately, the epidemic remained well below even the modest levels predicted by careful epidemiological analyses. More recent analyses indicate that even countries like Thailand, Cambodia and Myanmar-which were thought to have the most severe epidemics, with HIV/AIDS prevalence of one per cent or higher in the adult population-now have a less severe infection rate than previously believed. In the past decade, HIV infections declined remarkably in these countries, as well as in India, Nepal, Papua New Guinea and Malaysia. The absence of widespread sexual networks in the general population was an important advantage. But more could have been done. 
Many of the infections occurred in the context of a lingering policy dilemma.

It took considerable time for many countries in the region to recognise the threat of the epidemic and institutionalise large-scale responses. Success stories, though at varying degrees, are emerging. The 100 per cent condom use program, pioneered in Thailand in the 1990s, played a decisive role in reducing the spread of HIV. This program aimed at enforcing condom use at every commercial sexual encounter in the country. Though some criticised this policy as coercive, it offered hope at a time of brewing panic and other Asian countries began to adapt it when they saw the results. Condom use was not the norm in the developing societies of Asia-some countries had in place successful family planning policies that boosted the use of other contraceptive methods to very high levels while underplaying condoms, which were used sparingly. AIDS prevention agencies had to work hard to make condoms acceptable among men visiting sex workers. Health systems were weak and AIDS programs in developing countries relied heavily on outside funding. But even in the face of these obstacles, some programs achieved great results. The successful reversal of HIV infections and AIDS deaths in Cambodia through prevention and treatment programs, for example, demonstrates that with strong political will and international support it is possible to beat this devastating epidemic, even in poor societies.

The presence of multiple and often overlapping modes of transmissionsuch as male-female commercial sex, male-male sex and injecting drug use-makes AIDS epidemics especially challenging. Passing on contaminated blood is a very efficient mode of transmitting HIV. Drug users in Asia commonly share injecting equipment, so once HIV enters a network of drug injectors it quickly infects most members. This means that condom use programs alone are insufficient to prevent HIV in Asia, even in Thailand where a model condom policy evolved. A harm reduction approach to drug policy, which includes a needle-syringe exchange program as its core element, is necessary even if considered controversial. While this policy has worked successfully in advanced economies like Australia, authorities in Asia have found it difficult to accept, fearing that support for harm reduction may induce a further rise in illicit drug use. Evidence from small demonstration projects provided an argument to persuade sceptical policymakers, and in the 2000s some countries moved towards creating a more supportive legal and political environment. China, Indonesia, Malaysia and Vietnam have started to implement and scaleup harm reduction. These positive developments are promising.

W HILE large-scale epidemics seem to have been averted, the region is far from safe. HIV is still a matter of concern in developing economies. Amid several success stories, the epidemic trended upward in countries such as Indonesia, the Philippines, Bangladesh and Sri Lanka. The virus survives on social fault lines: drug users, gay men, sex workers and their customers-AIDS concentrates on a vulnerable segment of the population. Its targets are not randomly assembled. They come from social groups such as labour migrants, transport workers, disaffected youth from dysfunctional families, and women from poor, broken families. An adverse environment has been created in these groups by low awareness about the virus, stigma and the lack of legal reform. This environment has allowed AIDS to survive and expand in Asia.

Antiretroviral therapy (ART), which lengthens healthy life and increases the employment prospects of HIV carriers, has recently emerged as an indispensable pillar of anti-HIV programs. The use of ART to prevent mother-to-child transmission started in the mid-1990s. A recent HIV Prevention Trials Network study demonstrated that ART can make an HIV carrier less contagious and reduce the risk of transmission to uninfected partners. But many low-income countries in this region are still far from the ideal goal of universal ART treatment. Although it has become the norm in developed economies, only an estimated 18 per cent of pregnant women who carry HIV in South and Southeast Asia receive ART.

AIDS is now less likely to make inroads into the wider population than at any time in the three-decade long history of the epidemic. Yet it is likely to remain a matter of concern in Asia for several years. The virus is transmitted among people connected to sex industries and drug markets, and encouraged by internal and external population mobility, including the flow of migrant labourers. Some vulnerable groups such as injecting drug users and gay men still have an unacceptably high risk of contracting HIV. Until there is a policy response comprehensive enough to eliminate stigma against HIV carriers and sustain itself against external funding shocks, the virus will continue to infect too many people in Asia. EAFO

\section{Dr. Binod Nepal is an independent} scholar. 


\section{International migration in Asia's demographic transition}

GRAEME HUGO

VERY day in the Asia Pacific, millions of goods, financial products, services and people flow across borders. These movements are both a cause and consequence of the rapid economic growth enjoyed in the region. But the considerable liberalisation of regulations on capital and goods has not flowed through to international migration, even as masses of people have migrated across Asia.

The relationship between migration and economic and social development is complex. The demographic and economic circumstances of Asian countries are divergent, and, as a result, some countries suffer a labour shortage while others enjoy a surplus of workers. While there is an appreciation that the 'brain drain' losses of human capital caused as skilled people move away from home can have negative affects on lowincome countries, there is increasing evidence that emigration can have positive consequences for all parties. As Kofi Annan, a former SecretaryGeneral of the United Nations, put it: 'The potential for migrants to help transform their native countries has captured the imaginations of national and local authorities, international institutions and the private sector. There is an emerging consensus that countries can co-operate to create triple wins, for migrants, for their countries of origin and for the societies that receive them.'
In fact, migration affects development both positively and negatively. Getting the benefits depends on the government. Governments can intervene to facilitate those elements of migration that have positive impacts and to reduce or ameliorate those which have negative consequences. So far, poor governance and a lack of cross-border cooperation have meant Asia hasn't yet enjoyed the full benefits of migration between its borders.

So who migrates in Asia, and how do they do it? International migration data is generally poor, but it is possible to make some generalisations about the trends. First, women are increasingly active migrants-in several important flows they constitute the majority. Second, the 'migration industry'-made up of agents, travel providers, government officials and middlemen of various types-is growing rapidly. Third, the government is increasingly important in influencing both immigration and emigration. And fourth, there may now be as many undocumented

\section{.. . remittances are now}

\section{the largest source of}

external funding in

several Asia-Pacific

\section{countries}

migrants as those who entered foreign countries through authorised channels.

In the past two decades, many ordinary people in Asia, not just the elite, have come to consider whether moving overseas will improve their quality of life. Many people are also moving further away from their homes: there has been a significant increase not only in the movement between Asia-Pacific nations but also out of and into the region. Asia's migration is forced and unforced, documented and undocumented, permanent and non-permanent, workrelated and not work-related.

Arguably the most important reason for this migration boom is the growing demographic differences between countries. The Asia Pacific contains both high-income and low-income economies and their demographic trajectories have differed. On the one hand, high-income economies are experiencing low (and, in a few cases, negative) natural increases in population because of an extended period of low fertility. This is leading to slow natural growth. Eventually, the number of people of working age is projected to declineJapan is already experiencing this phenomenon. On the other hand, in low-income economies of the region, fertility decline has been more recent, although it has also been dramatic. Prolonged periods of very low fertility leads to a decline in the size and ageing of the workforce which can drive migration. 
One of the major characteristics of Asian migrants is that they tend to send money back to their families, even in times of stress. Remittances to South Asia, East Asia and the Pacific increased substantially in recent years and were less affected by the global financial crisis than other regions. Remittances to Asia-Pacific countries come from two main types of migrants. First, there is a diaspora of permanent settlers, most of whom live in OECD nations, and some of whom remit money to their families at home. Second, the Asia-Pacific is the pre-eminent source of the world's contract labour migrants. Almost all of these labourers remit money to their families in their home country.

It is difficult to measure exactly remittances in Asia and the Pacific: much of the movement is illegal, many of the migrants come from isolated areas and there is a long history of remitting money home through non-formal, traditional channels. The World Bank has estimated global remittances in 2011 at US\$501 billion, and the number has continued to increase despite the GFC. Remittances to less developed countries are now more than twice as great as official development assistance and almost as large as foreign direct investment. The scale is so large that remittances are now the largest source of external funding in several Asia-Pacific countries.

The increase in population mobility has been striking. The scale of the number who move has increased, the spatial patterning of where they move has grown more complex, and the composition of international movements has changed dramatically. International migration is both a cause and consequence of the rapid economic transformation in Asia, globalisation, political change and the

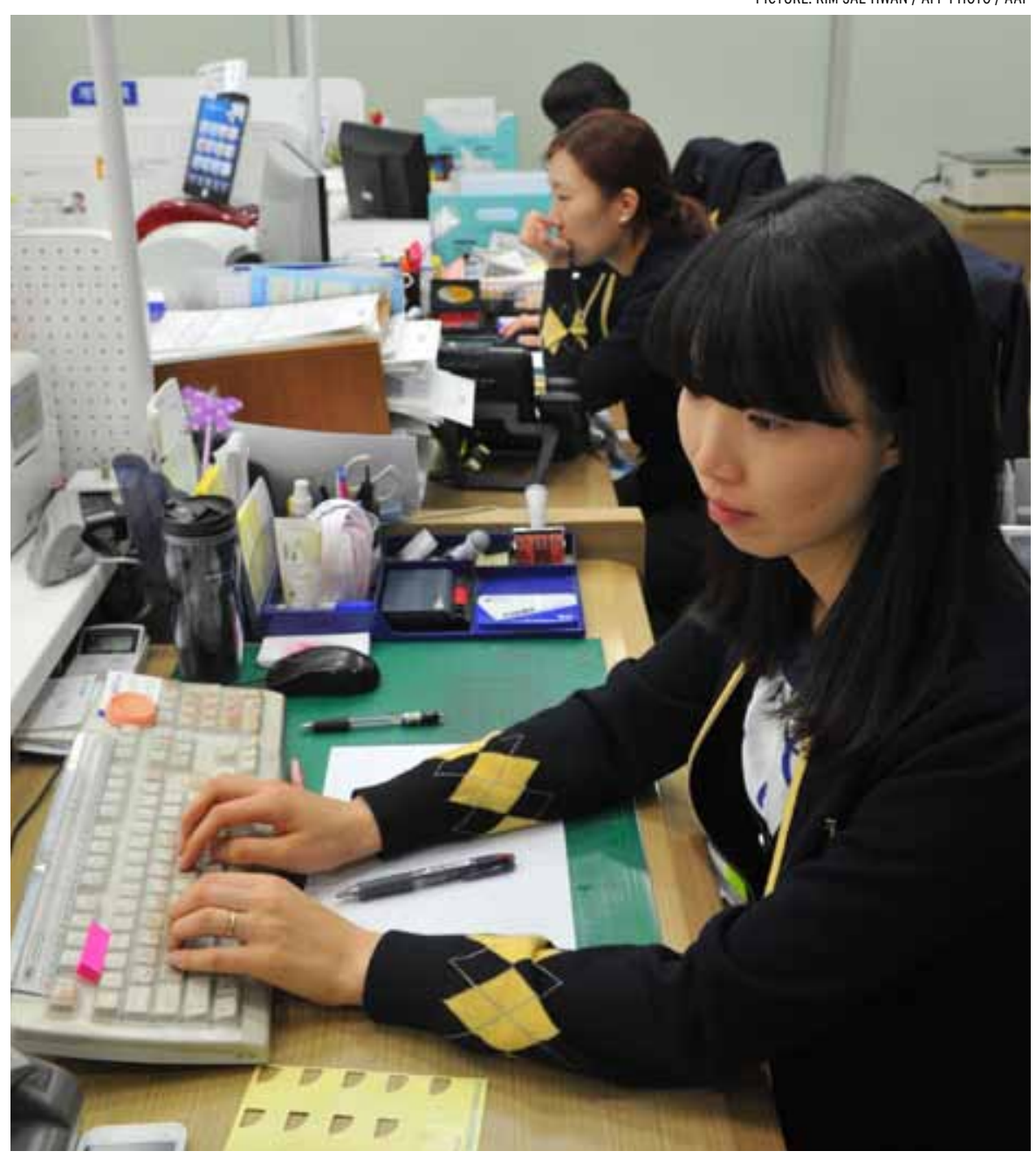

Office workers at a bank in Seoul. Women increasingly figure prominently in migration flows, and in some instances constitute a majority of those moving internationally.

development of education, among other factors and results. There is every indication that international population movements into, out of and within the region will continue to increase in scale and significance. While there is a great deal of variation between nations, it is clear that demographic, economic and social changes within the region will continue to favour an increase in international movement, as will differences between Asia and the Pacific on the one hand and Europe, North America and Australia/New Zealand on the other.

International migration will be a permanent structural feature of Asia-Pacific economies and societies. Policymakers in the region need to make a 'conceptual leap' with respect to international migration policy and recognise its long-term significance. Migration has the potential to improve the situation of people in poorer countries. But making this happen depends on policy coordination within countries of origin and destination.

EAFO

Graeme Hugo is Professor of Geography and Director of the Australian Population and Migration Research Centre at the University of Adelaide. 


\section{Australian}
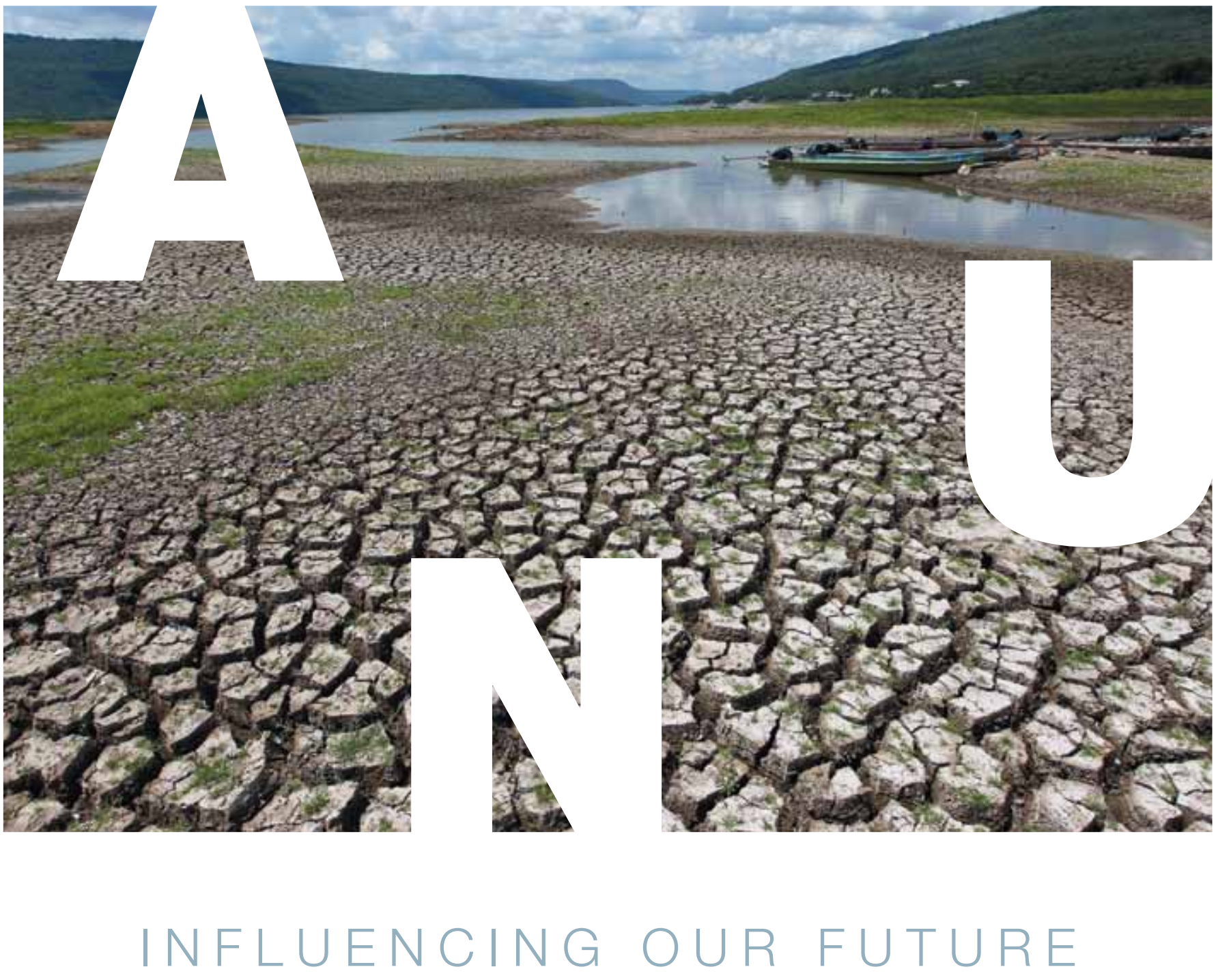

Crawford School is The Australian National University's public policy school, leading and shaping public policy debate in Australia, Asia and the Pacific, through research, professional education and policy engagement. Staff and visitors are active on government committees and play advisory roles across government, business and civil society.

As a student at Crawford School, you will be a valued member of Australia's leading public policy community and contribute to the impact being made to our water, food, energy and climate change challenges. You can explore your graduate coursework, research and executive education study options in the following fields:

\author{
> Public Policy \\ > Public Administration \\ > International and Development Economics \\ $>$ Environmental and Resource Economics \\ $>$ Environmental Management and Development \\ $>$ Climate Change \\ > Applied Anthropology and Participatory Development
}

Join Australia's leading public policy community today. 